\title{
A New Potassium-Based Coordination Polymer with Hydrogen Bonding and Zigzag Metallophilic Interactions
}

\author{
Zarin Moghadam ${ }^{1}$, Kamran Akhbari ${ }^{1, *}$, Jonathan White ${ }^{2}$, and Anukorn \\ Phuruangrat $^{3}$ \\ ${ }^{1}$ School of Chemistry, College of Science, University of Tehran, Tehran, Iran. \\ Tel.: +98 21 61113734; fax: +98 21 66495291. E-mail address: \\ akhbari.k@khayam.ut.ac.ir (K. Akhbari) \\ ${ }^{2}$ School of Chemistry and Bio21 Institute, The University of Melbourne, VIC 3010, \\ Australia \\ ${ }^{3}$ Department of Materials Science and Technology, Faculty of Science, Prince of Songkla \\ University, Hat Yai, Songkhla, Thailand.
}

\begin{abstract}
A new potassium-based coordination polymer $\left[\mathrm{K}\left(\mu_{7}-\mathrm{HTar}\right)\right]_{\mathrm{n}}(\mathbf{1}),\left(\mathrm{H}_{2} \mathrm{Tar}=(+)\right.$-tartaric acid), has been synthesized and structurally characterized by single crystal X-ray crystallography. It has a three-dimensional structure with zigzag $\mathrm{K} \cdots \mathrm{K}$ metallophilic interactions. Also widespread hydrogen bonding network in three-dimensional structure of 1 was observed. In order to evaluation the effects of concentration, ultrasonic irradiation and type of the solvents on morphology and thermal behavior of $\mathbf{1}$, some experiments were designed and six samples of $\mathbf{1}$ were synthesized under different conditions. These samples were characterized by IR spectroscopy, thermo gravimetric and differential thermal analyses (TG-DTA), X-ray powder diffraction (XRD) and Scanning Electron Microscopy (SEM).
\end{abstract}

Keywords: Coordination polymer; Potassium; metallophilic; Nanostructure; Ultrasonic; Solvent type.

This is the author manuscript accepted for publication and has undergone full peer review but has not been through the copyediting, typesetting, pagination and proofreading process, which may lead to differences between this version and the Version of Record. Please cite this article as doi: $10.1002 /$ aoc.4613

This article is protected by copyright. All rights reserved. 


\section{Introduction.}

Self-assembly of supramolecular polymers is a powerful tool for producing functional materials that combine several properties and may respond to external conditions. ${ }^{1-7}$ Recently, the construction of coordination supramolecular or coordination polymers has emerged as a powerful and versatile strategy for engineering metallo-polymers. ${ }^{8-12} \mathrm{~A}$ wide branch of supramolecular compounds is "Coordination polymer" which is achieved from coordination bonds between metal centers and appropriate ligands. Infinite coordination polymer particles represent an area of growing interest in chemistry and materials science due to their unique and profitable properties. ${ }^{13}$ Coordination polymers (CPs), including metal ions linked together by organic bridging ligands, ${ }^{1,2}$ are new class of polymeric materials that dwell between the interface of molecular coordination chemistry and material science. ${ }^{10}$ Synthesizing of these types of compound is frequently used in several applications such as electronics, catalysis, luminescence, drug delivery and separation. ${ }^{14-23}$ The process of self-assembly in coordination polymers can frequently be modified by various external factors, such as metal source, ligands, solvents, templates, $\mathrm{pH}$ value, temperature, different concentrations and so on, the same reactants can usually result in completely different structures because of the extreme sensitivity of self-assembly to the reaction conditions. ${ }^{24-31}$ A variety of methods such as Sol-Gel, microwave and sonochemical synthesis now exist for making numerous coordination polymers, with modest control over particle size and shape. ${ }^{13,17,26-30}$ Ultrasonic irradiation dramatically influences on the reactivity of different kind of inorganic solids. The use of ultrasound to accelerate chemical reactivity is becoming a common and widely applicable laboratory technique. The physical origins of the chemical effects of ultrasound lie principally in acoustic cavitation and other non-linear phenomena. ${ }^{31,32}$ The creation, expansion and collapse of bubbles in ultrasonically irradiated liquids generate localized hot spots from acoustic cavitation which are responsible for most homogeneous 
sonochemistry. Ultrasonic method, with benefit such as cost effectively and being environmentally friendly, is suitable for synthesizing of nanoscale coordination supramolecular compounds. ${ }^{31,32}$ Herein, we wish to report a potassium-based coordination polymer, $\left[\mathrm{K}\left(\mu_{7}-\mathrm{HTar}\right)\right]_{\mathrm{n}}$ (1) with zigzag chain $\mathrm{K} \cdots \mathrm{K}$ metallophilic interactions, which was characterized by IR spectroscopy and single-crystal X-ray diffraction. Prior to this study, some coordination polymers with metalophilic interaction such as $\left[\mathrm{Na}\left(\mu_{2}-\mathrm{Hdcpa}\right)\left(\mu_{3}-\mathrm{dcpa}\right)\right]_{n},(\text { Hdcpa }=2,4 \text {-dichlorophenoxyacetic acid })^{33},\left[\mathrm{Tl}\left(\mu_{3^{-}}\right.\right.$

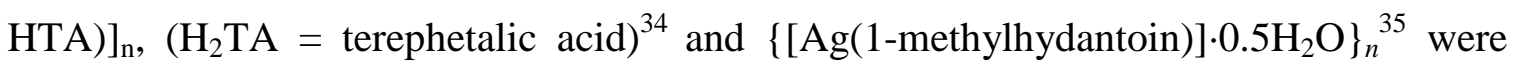
reported. Moreover, the effects of ultrasonic irradiation, concentration of initial reagents and types of solvents on formation of compound $\mathbf{1}$ nanostructures were investigated.

\section{Experimental}

\subsection{Materials and Physical Techniques}

All reagents and solvents for the synthesis and analysis were commercially available and were used as received. The molecular structure plots were prepared using Mercury. PARSONIC 15S ultrasonic bath (with the frequency $28 \mathrm{KHz}$ ) was used for the ultrasonic irradiation. Melting points were measured on an Electrothermal 9100 apparatus and are uncorrected. IR spectra were recorded using an Equinox 55 FT-IR spectrometer (Bruker, Bremen, Germany) in ATR form, in the range of $400-4000 \mathrm{~cm}^{-1}$ with $4.0 \mathrm{~cm}^{-1}$ resolution and the 16 scan's numbers. Intensity data for $\left[\mathrm{K}\left(\mu_{7}-\mathrm{HTar}\right)\right]_{\mathrm{n}}(\mathbf{1})$ was collected with an Oxford Diffraction SuperNova CCD diffractometer using Mo- $\mathrm{K}_{\alpha}$ radiation, the temperature during all data collections was maintained at 100.0(2) $\mathrm{K}$ using an Oxford Cryosystems cooling device. The structures were solved by direct methods and difference Fourier synthesis. ${ }^{36}$ Thermal ellipsoid plots were generated using the program ORTEP$3 .{ }^{37}$ within the WINGX suite of programs. ${ }^{38}$ The thermal behavior was measured with a PL-STA 1500 apparatus between 20 and $800{ }^{\circ} \mathrm{C}$, with a heating rate of $5{ }^{\circ} \mathrm{C} \cdot \mathrm{min}^{-}{ }^{1}$, under a nitrogen atmosphere. X-ray powder diffraction (XRD) measurements were performed 
using an X'pert diffractometer manufactured by Philips with monochromatized $\mathrm{CuK}_{\alpha}$ radiation $(\lambda=1.54056 \AA)$ with step-size of 0.01671 (degree). The $\mathrm{X}$-ray source was operated under voltage and current of $40 \mathrm{kV}$ and $30 \mathrm{~mA}$, respectively. Bragg-Brentano was used as a source - detector geometry with scintillation detector. Additional attachments or peripheral equipment such as anti-scatter slit $\left(1^{\circ}\right)$, divergence slit $\left(1^{\circ}\right)$, monochromator and soller slit $(0.04 \mathrm{rad})$ were also used in this diffractometer. The samples were prepared as fine powders on silicon based material. Simulated XRD powder patterns based on single crystal data were prepared using the Mercury software. The samples were characterized with a scanning electron microscope (Philips XL 30) with gold coating.

\subsection{Synthesis of $\left[\mathrm{K}\left(\mu_{7}-\mathrm{HTar}\right)\right]_{\mathbf{n}}(1)$ and preparation of its single crystals.}

$1.5 \mathrm{mmol}(0.225 \mathrm{gr})$ of (+)-tartaric acid $\left(\mathrm{H}_{2}\right.$ Tar) was dissolved in $20 \mathrm{~mL} \mathrm{H}_{2} \mathrm{O}$ and was mixed and stirred with solution of $3.0 \mathrm{mmol}(0.171 \mathrm{gr}) \mathrm{KOH}$ in $5 \mathrm{~mL} \mathrm{H}_{2} \mathrm{O}$ at $100{ }^{\circ} \mathrm{C}$ for an hour. After filtering, it was allowed to evaporate for several days and then suitable colorless crystals were obtained. d.p. $=275{ }^{\circ} \mathrm{C}$, yield: $0.116 \mathrm{~g}, 41.2 \%$ based on final product.

\subsection{Synthesis of $\left[\mathrm{K}\left(\mu_{7}-\mathrm{HTar}\right)\right]_{\mathrm{n}}(1)$ with altering concentrations of initial reagents as} the bulk samples and by sonochemical process.

In order to study the effect of various concentrations on synthesis of compound $\mathbf{1}$ as a bulk sample, first, $4 \mathrm{mmol}(0.600 \mathrm{gr})$ of $\mathrm{H}_{2} \mathrm{Tar}$ in $20 \mathrm{~mL} \mathrm{H}_{2} \mathrm{O}$ and $8 \mathrm{mmol}(0.456 \mathrm{gr})$ of $\mathrm{KOH}$ in $5 \mathrm{~mL} \mathrm{H}_{2} \mathrm{O}$ were mixed, heated and stirred at $100{ }^{\circ} \mathrm{C}$ for 3 hours. Then, it was allowed to evaporate for several days. Consequently, the white precipitate was formed (1LWB). d.p. for $1 \mathrm{LWB}=270{ }^{\circ} \mathrm{C}$, yield: $0.580 \mathrm{~g}, 77.0 \%$ based on final product. The second reaction condition was similar to previous one except $16 \mathrm{mmol} \mathrm{KOH}(0.912 \mathrm{gr})$ which was solved in $5 \mathrm{~mL} \mathrm{H}_{2} \mathrm{O}$, was added to $8 \mathrm{mmol}$ of $\mathrm{H}_{2}$ Tar (1.200 gr) in $20 \mathrm{~mL}$ 
water. White precipitate was formed which was dried at room temperature (1HWB). d.p. for $1 \mathrm{HWB}=271{ }^{\circ} \mathrm{C}$, yield: $0.731 \mathrm{~g}, 48.4 \%$ based on final product. To consider the effect of ultrasonic irradiation on formation of compound $1,8 \mathrm{mmol}\left(1.200 \mathrm{gr}\right.$ ) of $\mathrm{H}_{2}$ Tar in 20 $\mathrm{mL} \mathrm{H}_{2} \mathrm{O}$ and $16 \mathrm{mmol}(0.912 \mathrm{gr})$ of $\mathrm{KOH}$ in $5 \mathrm{~mL} \mathrm{H}_{2} \mathrm{O}$ were mixed under the ultrasonic irradiation. The obtained precipitates were filtered and dried at room temperature (1HWS). d.p. for $1 \mathrm{HWS}=250{ }^{\circ} \mathrm{C}$, yield: $0.870 \mathrm{~g}, 57.6 \%$ based on final product.

\subsection{Synthesis of $\left[K\left(\mu_{7}-H T a r\right)\right]_{n}(1)$ nanostructure in various solvent by sonochemical process.}

To consider the effect of different solvents on formation of compound $\mathbf{1}$, three types of reaction were designed. First, we used ultrasonic bath with 4:8 mmol concentrations of initial reagents $\left(\mathrm{H}_{2}\right.$ Tar: $\left.\mathrm{KOH}\right)$ in a solution mixture of $3 \mathrm{~mL} \mathrm{H}_{2} \mathrm{O}$ and $7 \mathrm{~mL}$ acetonitrile. The precipitates were obtained after 3 hours and then filtered, subsequently washed with water and then dried (1LAS), d.p. $=251{ }^{\circ} \mathrm{C}$, yield: $0.620 \mathrm{~g}, 82.0 \%$ based on final product. Second and third reactions were performed under the same conditions, however, with different solvents, ethanol, (1LES, d.p. $=272{ }^{\circ} \mathrm{C}$, yield: $0.681 \mathrm{~g}, 90.2 \%$ based on final product) and methanol, (1LMS, d.p. $=271^{\circ} \mathrm{C}$, yield: $0.640 \mathrm{~g}, 84.8 \%$ based on final product).

\section{Result and discussion.}

The reaction between (+)-tartaric acid $\left(\mathrm{H}_{2} \mathrm{Tar}\right)$ and $\mathrm{KOH}$ provided a crystalline material of the general formula $\left[\mathrm{K}\left(\mu_{7}-\mathrm{HTar}\right)\right]_{\mathrm{n}}(\mathbf{1})$. Determination of the structure of compound $\mathbf{1}$ by X-ray crystallography (Tables S1 and S2 in the SI) showed that it has one type of K atom with $\mathrm{KO}_{9}$ coordination sphere (Figure 1a). $\mathrm{H}_{2}$ Tar was not deprotonated completely and HTar is bridging between seven $\mathrm{K}$ ions and can be considered as heptadentate ligand (Figure $1 \mathrm{~b}$ ). Each of the $-\mathrm{COOH}$ and $-\mathrm{COO}^{-}$groups of $\mathrm{HTar}^{-}$bridges between three $\mathrm{K}$ ions (Figure 1b). The two -OH group of HTar showed different coordination behavior.

This article is protected by copyright. All rights reserved. 
One of them is coordinated a $\mathrm{K}$ ion which has coordination bond with - $\mathrm{COO}^{-}$group and another $-\mathrm{OH}$ is coordinated to infinite $\mathrm{K}$ ion (Figure $1 \mathrm{~b}$ ). Compound $\mathbf{1}$ is a threedimensional coordination polymer (Figure 1c) and has zigzag chain $\mathrm{K} \cdots \mathrm{K}$ metallophilic interactions with distance of 4.0479(7) $\AA$ (Table S2) which is lower than the sum of the vander Waals radii of two $\mathrm{K}$ atoms ${ }^{39}(5.50 \AA$, Figure $2 \mathrm{a})$. The neighbor three $\mathrm{K}$ ions have the bond angle of $139.939(19)^{\circ}$ (Table S2 in the SI). HTar with variety of hydrogen bonding donors and acceptors formed widespread hydrogen bonding network in threedimensional structure of 1 (Table S3 in the SI and Figure 2b). Thus the broad absorption bond around $3000-3700 \mathrm{~cm}^{-1}$ in its IR spectrum (Figure 3a) is due to some reasons: i. deprotonation of the carboxylic acid groups in $\mathrm{H}_{2}$ Tar were not occurred completely, ii. presence of two $-\mathrm{OH}$ groups on $\mathrm{H}_{2}$ Tar and iii. widespread hydrogen bonding network in the structure of $\mathbf{1}$. The absorption bands in the frequency of 1100 and $1580 \mathrm{~cm}^{-1}$ attributed to $\mathrm{C}$ - OandHCqupotippinance of $\mathrm{C}=\mathrm{O}$ bond in $\mathrm{COOH}$ group of $\mathrm{HTar}^{-}$in the frequency of $1580 \mathrm{~cm}^{-1}$ is as a result of its coordination to $\mathrm{K}$ ion. Also the absorption bands in the frequency of 1300 and $1400 \mathrm{~cm}^{-1}$ attributed to $v_{\text {sym }}$ and $v_{\text {asym }}$ of $-\mathrm{COO}^{-}$group in $\mathbf{1}$.

In order to evaluation the effects of concentration, ultrasonic irradiation and types of the solvent on morphology of compound 1, we designed some experiments and synthesized six samples of 1 under different conditions (Table 1).

First, for considering the effect of concentration of initial reagents we performed two reactions for synthesizing bulk sample of 1 with $\mathrm{H}_{2}$ Tar: $\mathrm{KOH}$ molar ratios of 4:8 (1LWB) and 8:16 (1HWB). The FT-IR spectra of them (Figure 3b,c) showed that 1LWB and 1HWB have the same structure as the crystal sample (Figure 3a). Figure 4a shows the simulated XRD pattern from single crystal X-ray data of 1 . Figure $4 b, c$ show the XRD patterns of the typical bulk samples of 1LWB and 1HWB. Acceptable matches with slight differences in $2 \theta$, were observed between the simulated from single-crystal X-ray data pattern (Figure 4a) and that from the experimental powder X-ray diffraction pattern 
of 1LWB and 1HWB (Figure 4b,c). The SEM image of 1LWB indicates the formation of compound 1 spongy microstructure with nanostructural surface (Figure 5a). By concentration increase, SEM image (Figure 5b) did not show the spongy structure in 1HWB but existence of nanoparticles in its surface is approved. Thus with concentration increase, the hollow spaces was filled. In order to study the effect of ultrasonic irradiation on forming compound $\mathbf{1}$, another reaction with 8:16 molar ratio of $\mathrm{H}_{2} \mathrm{Tar}: \mathrm{KOH}$ was performed by sonochemical process. The FT-IR spectrum (Figure 3d) approved that this sample also has the same structure as the crystal sample (Figure 3a). Figure $4 \mathrm{~d}$ shows the XRD patterns of the typical sonochemical prepared sample of 1HWS. Acceptable matches were observed between the simulated from single-crystal X-ray data pattern (Figure 4a) and that from the experimental powder X-ray diffraction pattern of 1HWS (Figure 4d). The SEM image of 1HWS (Figure 5c) did not show any difference in comparison with 1HWB (Figure 5b) but its surface composed from nanocubes of 1 instead of nanoparticles in 1HWB. Thus ultrasonic irradiation has led to directional growth of nanostructures on surface of compound $\mathbf{1}$ microstructure.

Second for studies the types of the solvent effect on morphology of compound $\mathbf{1}$, three reactions in the presence of acetonitrile (1LAS), ethanol (1LES) and methanol (1LMS) with 4:8 ratios of initial reagents were performed under ultrasonic irradiation (Table 1). The FT-IR spectra of them (Figure 3e-g) approved the formation of them successfully. Acceptable matches were observed between the simulated from single-crystal X-ray data pattern (Figure 4a) and that from the experimental powder X-ray diffraction patterns of 1LAS, 1LES and 1LMS samples (Figure 4e-g). Figure 6a,b show the SEM images of 1LAS and 1LES. A comparison between them indicated that both of them have similar surface composed from small nanoparticles and the solvents only affected on microstructure morphology of 1. On the other hand with methanol (1LMS) instead of acetonitrile (1LAS) and ethanol (1LES) solvents, spongy microstructure with regular 
nanostructure surface was obtained (Figure 6c). It seems that the two factors of concentration and solvent can affect on formation of spongy microstructures of $\mathbf{1}$.

TG-DTA data (Figure 7a) indicated that compound 1LWB is stable up to $255^{\circ} \mathrm{C}$. The endothermic mass loss of $3.6 \%$ between $160-180{ }^{\circ} \mathrm{C}$ may be attributed to adsorption species on the surface of $1 \mathrm{LWB}$. Further mass loss of it up to $500{ }^{\circ} \mathrm{C}$ attributed to removal of other species such as $\mathrm{CO}_{2}$ gas molecules (Figure 7a). 1HWB showed similar thermal behavior to 1LWB (Figure 7b). This similarity is expected because these two samples were synthesized in the same conditions with different concentration of initial reagents. 1HWS which was synthesized by sonochemical process is stable up to $221{ }^{\circ} \mathrm{C}$ (Figure 7c). No mass loss was observed between $160-180{ }^{\circ} \mathrm{C}$. Thus it seems that ultrasonic waves prevented the adsorption of external species on the surface of 1HWS. Thermal behavior of $\mathbf{1 H W S}$ after $221^{\circ} \mathrm{C}$ is similar to the two previous samples (Figure 7c). A comparison between the thermal behaviors of 1LAS, 1LES and 1LMS (Figure 7d$\mathrm{f}$, which were synthesized in acetonitrile, ethanol and methanol, respectively) indicated that 1LAS (Figure 7d) and 1LES (Figure 7e) have similar behavior and the strange thing in their TG curves is that both of them have continues gradual mass loss up to $220{ }^{\circ} \mathrm{C}$. After $220{ }^{\circ} \mathrm{C}$ similar behavior (Figure 7d,e) to previous samples (Figure 7a-c) were observed. Finally 1LMS sample has similar thermal behavior (Figure 7f) to other previous samples (Figure 7a-c). It seems that the type of solvent that used in synthesis of compound $\mathbf{1}$ has some effects on thermal stability of them and acetonitrile and ethanol are not good solvents for this proposes.

\section{Conclusion.}

In summary, a new three-dimensional potassium-based coordination polymer $\left[\mathrm{K}\left(\mu_{7^{-}}\right.\right.$ HTar) $]_{n}$ (1) with zigzag chain $\mathrm{K} \cdots \mathrm{K}$ metallophilic interactions has been synthesized and structurally characterized by single crystal X-ray crystallography. Also widespread 
hydrogen bonding network in three-dimensional structure of $\mathbf{1}$ was observed. $\mathrm{K}$ atom has $\mathbf{K O}_{9}$ coordination sphere in $\mathbf{1} . \mathrm{H}_{2}$ Tar was not deprotonated completely and HTar ${ }^{-}$is bridging between seven $\mathrm{K}$ ions and can be considered as heptadentate ligand. The two $\mathrm{OH}$ group of HTar ${ }^{-}$showed different coordination behavior. One of them is coordinated a $\mathrm{K}$ ion which has coordination bond with $-\mathrm{COO}^{-}$group and another $-\mathrm{OH}$ is coordinated to infinite $\mathrm{K}$ ion. The broad absorption bond around $3000-3700 \mathrm{~cm}^{-1}$ in its IR spectrum of $\mathbf{1}$ is due to partial deprotonation of the carboxylic acid groups in $\mathrm{H}_{2}$ Tar, presence of two $\mathrm{OH}$ groups on $\mathrm{H}_{2}$ Tar and widespread hydrogen bonding network in the structure of it. In order to evaluation the effects of concentration, ultrasonic irradiation and types of the solvent on morphology and thermal behavior of $\mathbf{1}$, six samples of it were synthesized under different conditions. Concentration of initial reagents can change the morphology of the final product and with low concentration of initial reagents, spongy microstructures was formed. Ultrasonic irradiation was led to directional growth of nanostructures on surface of compound $\mathbf{1}$ microstructure. Also types of the solvent can affect on morphology of $\mathbf{1}$. With methanol instead of acetonitrile and ethanol, spongy microstructure with regular nanostructure surface was obtained. The solvent used in synthesis of $\mathbf{1}$ has some effects on thermal stability of them and acetonitrile and ethanol are not good solvents for this proposes.

\section{Supplementary material.}

Complete bond lengths and angles, co-ordinates and displacement parameters have been deposited at Cambridge Crystallography Data Center. Supplementary data are available from the CCDC, 12 Union Road, Cambridge CB2 1EZ, UK on request, quoting the deposition number 1845659 for compound 1.

\section{Acknowledgements}


The authors would like to acknowledge the financial support of University of Tehran for this research under grant number 01/1/389845.

\section{References}

[1] O. Ikkala, G.t t. Brinke, Science, 2002, 295, 2407-2409.

[2] R. Banerjee, A. Phan, B. Wang, C. Knobler, H. Furukawa, M. O’Keeffe, O. M. Yaghi, Science, 2008, 319, 939-943.

[3] S. Kitagawa, R. Kitaura, S. Noro, Angew. Chem, 2004, 43, 2334-2375.

[4] D. Bradshaw, A. Garai, J. Huo, Chem. Soc. Rev, 2012, 41, 2344-2381.

[5] K. Akhbari, A. Morsali, Polyhedron, 2011, 30, 1456-1462.

[6] Qi Zhang, Da

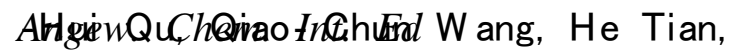

,2015,127,16015-16019.

[7] Q. Zhang, C.-Y. Shi, D.-H. Qu, Y.-T. Long, B. L. Feringa, H. Tian, Sci. Adv. 2018, 4, eaat8192.

[8] K. Akhbari, A. Morsali, Inorg. Chem., 2013, 52, 2787-2789.

[9] Q. Zhang, D.-H. Qu, Q.-C. Wang, H. Tian, Angew. Chem. Int. Ed. 2015, 54, 15789 15793.

[10] S. Hornig, I. Manners, G. R. Newkome, U. S. Schubert, Macromol Rapid Commun, 2010, 31, 771-771.

[11] A.S. Abd-El-Aziz, I. Manners, Frontiers in Transition Metal-Containing Polymers, Hoboken, New Jersey, Wiley, 2007.

[12] V. Chandrasekhar, Inorganic and Organometallic Polymers, New York, Springer, 2005.

[13] A. M. Spokoyny, D. Kim, A. Sumreina, Ch. A. Mirkin, Chem. Soc. Rev, 2009, 38 1217-1227.

[14] V. Stavila, A. A. Talin, M. D. Allendorf, Chem. Soc. Rev, 2014, 43, 5994-6010.

[15] Z. Ma, B. Moulton, Coord. Chem. Rev, 2011, 255, 1623-1641.

This article is protected by copyright. All rights reserved. 
[16] J.R. Li, J. Sculley, H.C. Zhou, Chem. Rev, 2012, 112, 869-932.

[17] J. Liu, L. Chen, H. Cui, J. Zhang, L. Zhang, C.Y. Su, Chem. Soc. Rev, 2014, 43, 6011-6061.

[18] Z. Hu, B. J. Deibert, J. Li, Chem. Soc. Rev, 2014, 43, 5815-5840.

[19] K. Akhbari, A. Morsali, S. Rafiei, M. Zeller, J. Organomet. Chem, 2008, 693, 257262.

[20] K. Akhbari, A. Morsali, Inorg. Chem. Commun, 2007, 10, 1189-1193.

[21] R. Bashiri, K. Akhbari, A. Morsali, M. Zeller, J. Organomet. Chem, 2008,693, 19031911.

[22] K. Akhbari, A. Morsali, L.G. Zhu, J. Mol. Struct, 2008, 891, 132-137.

[23] K. Akhbari, A. Morsali, Inorg. Chem, 2013, 52, 2787-2789.

[24] H. Y. Li, L. H. Cao, Y. L. Wei, H. Xu, S. Q. Zang, CrystEngComm, 2015,17, 62976307.

[25] L. Zhou, Y.S. Xue, Y. Xu, J. Zhang, H.-B. Du, CrystEngComm, 2013,15, 73157320 .

[26] S. Hojaghani, K. Akhbari, M. H. Sadr, A. Morsali, Inorg. Chem. Commun, 2014, 44, $1-5$.

[27] E. Mirzadeh, K. Akhbari, A. Phuruangrat, F. Costantino, Ultrason. Sonochem, 2017,35, 382-388.

[28] Y. Noori, K. Akhbari, A. Phuruangrat, Ultrason. Sonochem, 2017, 35, 36-44.

[29] Y. Noori, K. Akhbari, A. Phuruangrat, F. Costantino, Ultrason. Sonochem, 2018, 40, $17-20$.

[30] K. Akhbari, S. Karami, Z. Saedi, Ultrason. Sonochem, 2018, 42, 640-646.

[31] F. Shahangi Shirazi, K. Akhbari, Ultrason. Sonochem, 2016, 31, 51-61.

[32] O. K. Farha, I. Eryazici, N. Ch Jeong, B. G. Hauser, Ch. E. Wilmer, A. A. Sarjeant, R. Q. Snurr, S. T. Nguyen, A. Ö Yazaydın, J. T. Hupp, J. Am. Chem. Soc, 2012,134, 15016-15021.

This article is protected by copyright. All rights reserved. 
[33] F. Shahangi Shirazi, K. Akhbari, J. Iran. Chem. Soc, 2017, 14, 1519-1527.

[34] E. Mirzadeh, K. Akhbari, J. White, Appl Organometal Chem. 2018, e4313, 1-8.

[35] M. Puszynska-Tuszkanow, Z. Staszak, T. Misiaszek, M. T.Klepka, A. Wolska, A. Drzewiecka-Antonik, H. Faltynowi,cz, M. Cieslak-Golonka, Chem. Phys. Lett, 2014, 597, 94-98.

[36] G. M. Sheldrick, Acta Cryst. Sect. C, 2015, 71, 3-8.

[37] L. J. Farrugia, J. Appl. Cryst, 1997, 30, 565-565.

[38] L. J. Farrugia, J. Appl. Cryst, 1999, 32, 837-838.

[39] A. Bondi, J. phys. Chem, 1964, 68, 441-451.

Table 1. A summary of reaction conditions for synthesis six samples of $\left[\mathrm{K}\left(\mu_{7}-\mathrm{HTar}\right)\right]_{\mathrm{n}}$ (1).

\begin{tabular}{|c|c|c|c|c|}
\hline Compound Label & $\begin{array}{c}\mathrm{H}_{2} \text { Tar:KOH ratio } \\
\text { (mmol) }\end{array}$ & $\begin{array}{l}\text { Ultrasonic } \\
\text { Irradiation }\end{array}$ & Solvent & Thermal behavior \\
\hline 1LWB & $4: 8$ & No & Water & $\begin{array}{l}\text { It is stable up to } 255{ }^{\circ} \mathrm{C} \text {. } \\
\text { Mass loss of it up to } 500 \\
{ }^{\circ} \mathrm{C} \text { attributed to removal of } \\
\text { other species such as } \mathrm{CO}_{2} \\
\text { gas molecules. }\end{array}$ \\
\hline 1HWB & $8: 16$ & No & Water & $\begin{array}{l}\text { It showed similar thermal } \\
\text { behavior to } 1 \mathrm{LWB} \text {. }\end{array}$ \\
\hline 1HWS & $8: 16$ & Yes & Water & $\begin{array}{l}\text { It is stable up to } 221{ }^{\circ} \mathrm{C} \text {. } \\
\text { Thermal behavior of } \\
\text { 1HWS after } 221{ }^{\circ} \mathrm{C} \text { is }\end{array}$ \\
\hline
\end{tabular}

This article is protected by copyright. All rights reserved. 


\begin{tabular}{|c|c|c|c|c|}
\hline & & & & $\begin{array}{l}\text { similar to the two previous } \\
\text { samples. }\end{array}$ \\
\hline 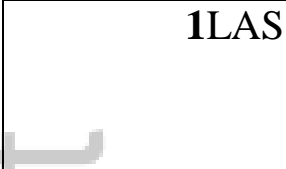 & $4: 8$ & Yes & Acetonitrile & $\begin{array}{l}\text { TG curve of 1LAS have } \\
\text { continues gradual mass } \\
\text { loss up to } 220^{\circ} \mathrm{C} \text {. }\end{array}$ \\
\hline ) & $4: 8$ & Yes & Ethanol & $\begin{array}{l}\text { It showed similar thermal } \\
\text { behavior to 1LAS }\end{array}$ \\
\hline 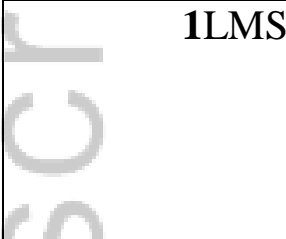 & $4: 8$ & Yes & Methanol & $\begin{array}{l}\text { It has similar thermal } \\
\text { behavior to other previous } \\
\text { samples (1LWB, 1HWB, } \\
\text { 1HWS) }\end{array}$ \\
\hline
\end{tabular}

Figure 1. Primary structural building unit in $\left[\mathrm{K}\left(\mu_{7}-\mathrm{HTar}\right)\right]_{\mathrm{n}}$ (1) indicating a) coordination sphere around $\mathrm{K}$ ion and b) coordination behavior of $\mathrm{HTar}^{-}$and c) a fragment of threedimensional coordination polymer in $\mathbf{1},(\mathrm{K}=$ violet, $\mathrm{O}=\mathrm{red}, \mathrm{C}=$ gray and $\mathrm{H}=$ white, in a and $\mathrm{c}$ hydrogen atoms have been omitted for clarity).

Figure 2. Illustrating a) zigzag $\mathrm{K} \cdots \mathrm{K}$ interactions in $\left[\mathrm{K}\left(\mu_{7}-\mathrm{HTar}\right)\right]_{\mathrm{n}}$ (1) with pink dashed line along the crystallographic $\mathrm{b}$ axis and $\mathrm{b}$ ) three-dimensional hydrogen bonding network in $\mathbf{1}$ with green dashed line, $(\mathrm{K}=$ violet, $\mathrm{O}=$ red, $\mathrm{C}=$ gray and $\mathrm{H}=$ white, in a hydrogen atoms have been omitted for clarity).

This article is protected by copyright. All rights reserved. 
Figure 3. IR spectra of a) single crystal of compound $\left[\mathrm{K}\left(\mu_{7}-\mathrm{HTar}\right)\right]_{\mathrm{n}}(\mathbf{1})$, compound $\mathbf{1}$ (as bulk sample) prepared with b) 4:8 $\mathrm{mmol}$ of $\mathrm{H}_{2}$ Tar and $\mathrm{KOH}$ (1LWB), c) 8:16 mmol of $\mathrm{H}_{2}$ Tar and $\mathrm{KOH}(\mathbf{H W B})$, d) compound 1 synthesized by sonochemical process with 8:16 mmol of $\mathrm{H}_{2}$ Tar and $\mathrm{KOH}$ (1HWS), compound 1 prepared by sonochemical process with 4:8 mmol of $\mathrm{H}_{2}$ Tar and $\mathrm{KOH}$ in 3:7 mixture of e) Water:MeCN (1LAS), f) Water:Ethanol (1LES) and g) Water:Methanol (1LMS).

Figure 4. XRD patterns; a) simulated pattern based on single crystal data of compound $\left[\mathrm{K}\left(\mu_{7}-\mathrm{HTar}\right)\right]_{\mathrm{n}}(\mathbf{1})$, compound $\mathbf{1}$ (as bulk sample) prepared with b) 4:8 $\mathrm{mmol}$ of $\mathrm{H}_{2} \mathrm{Tar}$ and $\mathrm{KOH}(1 \mathrm{LWB})$, c) 8:16 mmol of $\mathrm{H}_{2}$ Tar and $\mathrm{KOH}(1 \mathrm{HWB})$, d) compound 1 synthesized by sonochemical process with 8:16 mmol of $\mathrm{H}_{2}$ Tar and $\mathrm{KOH}$ (1HWS), compound 1 prepared by sonochemical process with 4:8 mmol of $\mathrm{H}_{2}$ Tar and $\mathrm{KOH}$ in 3:7 mixture of e) Water:MeCN (1LAS), f) Water:Ethanol (1LES) and g) Water:Methanol (1LMS)

Figure 5. SEM images of compound 1 (as bulk sample) prepared with a) 4:8 mmol of $\mathrm{H}_{2}$ Tar and $\mathrm{KOH}(\mathbf{1 L W B})$, b) 8:16 mmol of $\mathrm{H}_{2}$ Tar and $\mathrm{KOH}(\mathbf{H W B})$ and c) compound 1 synthesized by sonochemical process with 8:16 mmol of $\mathrm{H}_{2} \mathrm{Tar}$ and $\mathrm{KOH}$ (1HWS).

Figure 6. SEM images of compound 1 prepared by sonochemical process with 4:8 mmol of $\mathrm{H}_{2}$ Tar and $\mathrm{KOH}$ in 3:7 mixture of e) Water:MeCN (1LAS), f) Water:Ethanol (1LES) and g) Water:Methanol (1LMS).

Figure 7. Thermal behavior of compound 1 (as bulk sample) prepared with a) 4:8 mmol of $\mathrm{H}_{2}$ Tar and $\mathrm{KOH}(\mathbf{1 L W B})$, b) 8:16 mmol of $\mathrm{H}_{2}$ Tar and $\left.\mathrm{KOH}(\mathbf{1 H W B}), \mathrm{c}\right)$ compound 1 synthesized by sonochemical process with 8:16 mmol of $\mathrm{H}_{2} \mathrm{Tar}$ and $\mathrm{KOH}$ (1HWS), compound 1 prepared by sonochemical process with 4:8 mmol of $\mathrm{H}_{2} \mathrm{Tar}$ and $\mathrm{KOH}$ in 3:7 mixture of d) Water:MeCN (1LAS), e) Water:Ethanol (1LES) and f) Water:Methanol (1LMS). 


\section{A table of contents}

\begin{tabular}{|l|l|}
\hline $\begin{array}{l}\text { A New Potassium-Based } \\
\text { Coordination Polymer } \\
\text { with Hydrogen Bonding } \\
\text { and Zigzag Metallophilic }\end{array}$ & $\begin{array}{l}\text { zigzag } \mathrm{K} \cdots \mathrm{K} \text { metallophilic interactions } \\
\text { has been synthesized and structurally } \\
\text { Interactions }\end{array}$ \\
characterized. A widespread hydrogen \\
bonding network in 3D structure of it \\
$\begin{array}{l}\text { Zarin Moghadam, } \\
\text { Kamran Akhbari, } \\
\text { Jonathan White, } \\
\text { Anukorn Phuruangrat }\end{array}$ \\
concentration, ultrasonic irradiation \\
and type of the solvents on \\
morphology and thermal behavior of it \\
was investigated.
\end{tabular}




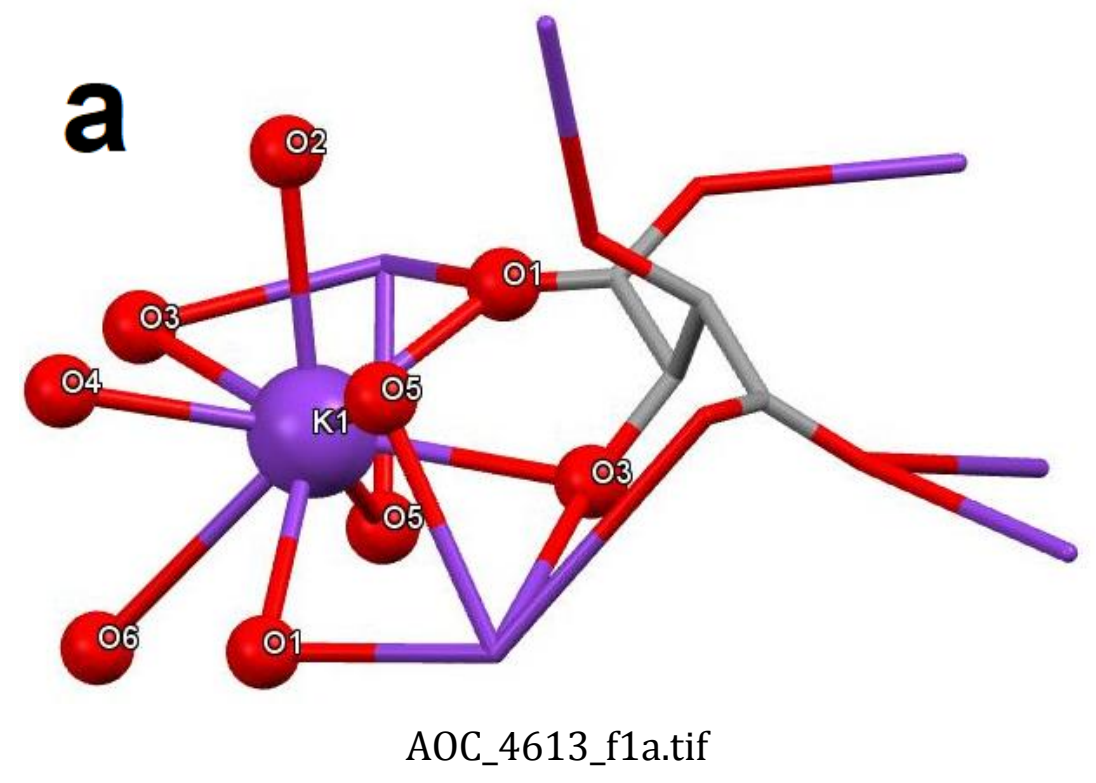

This article is protected by copyright. All rights reserved. 


\section{b}

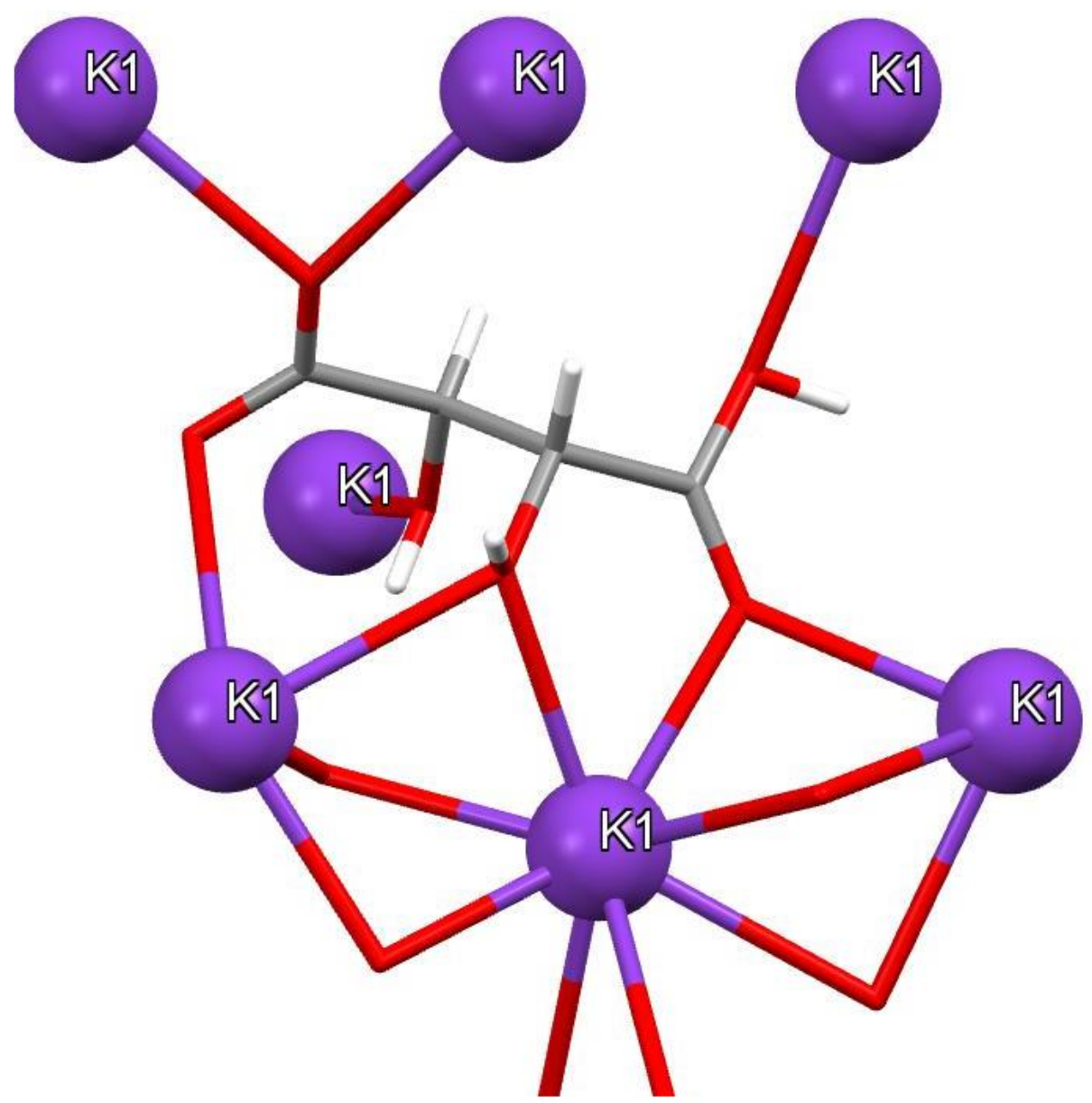

AOC_4613_f1b.tif

This article is protected by copyright. All rights reserved. 


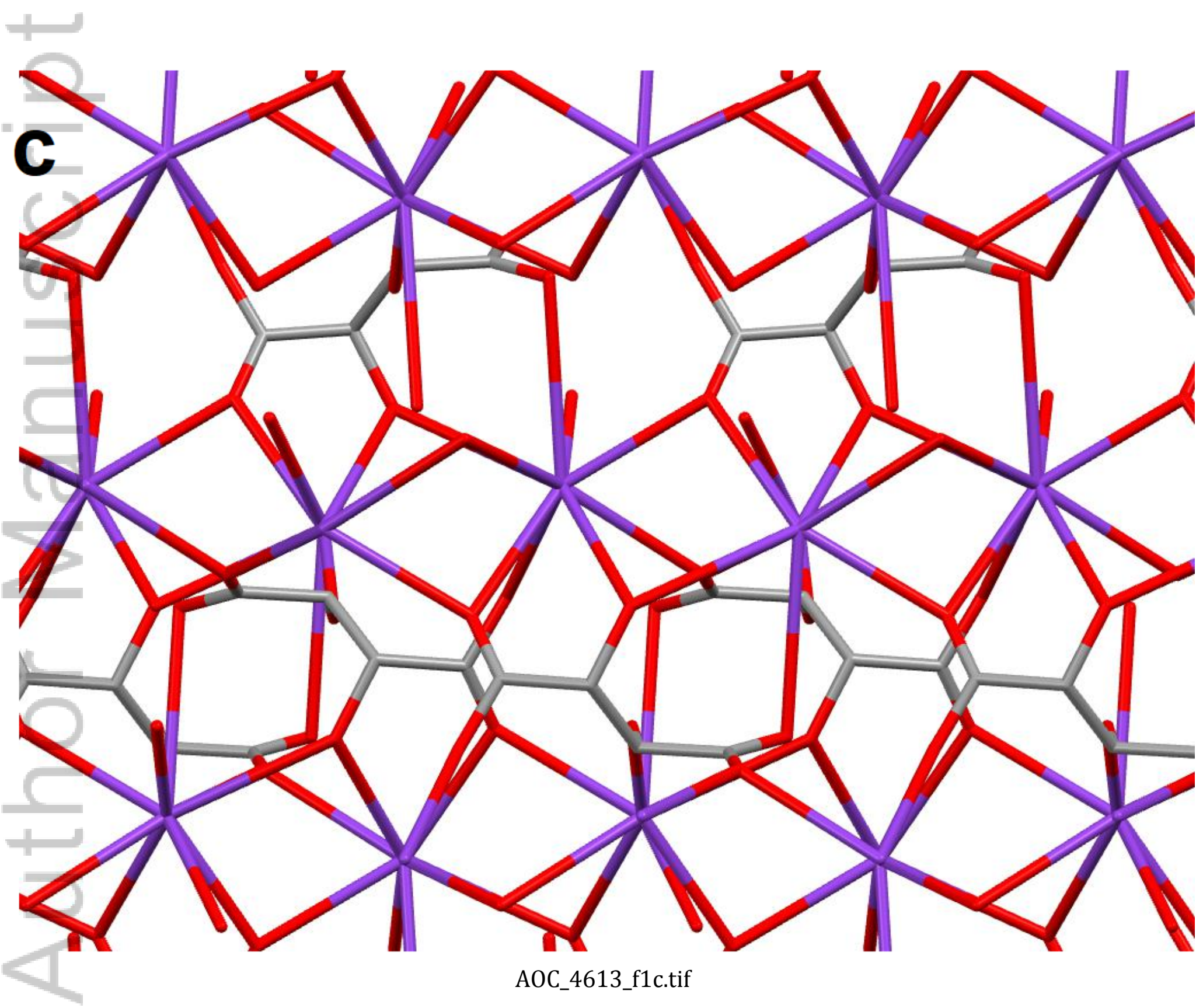

This article is protected by copyright. All rights reserved. 


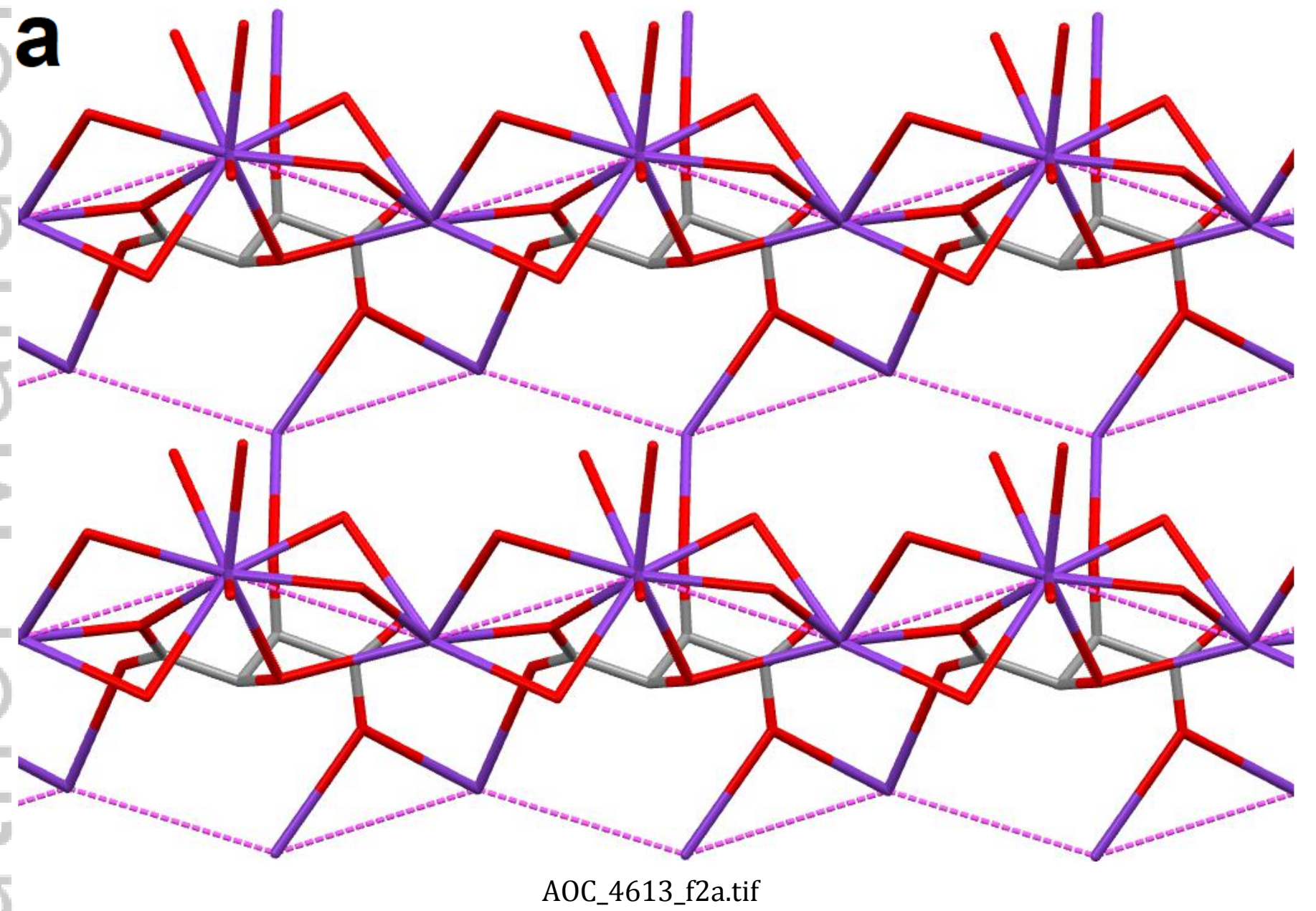

This article is protected by copyright. All rights reserved. 


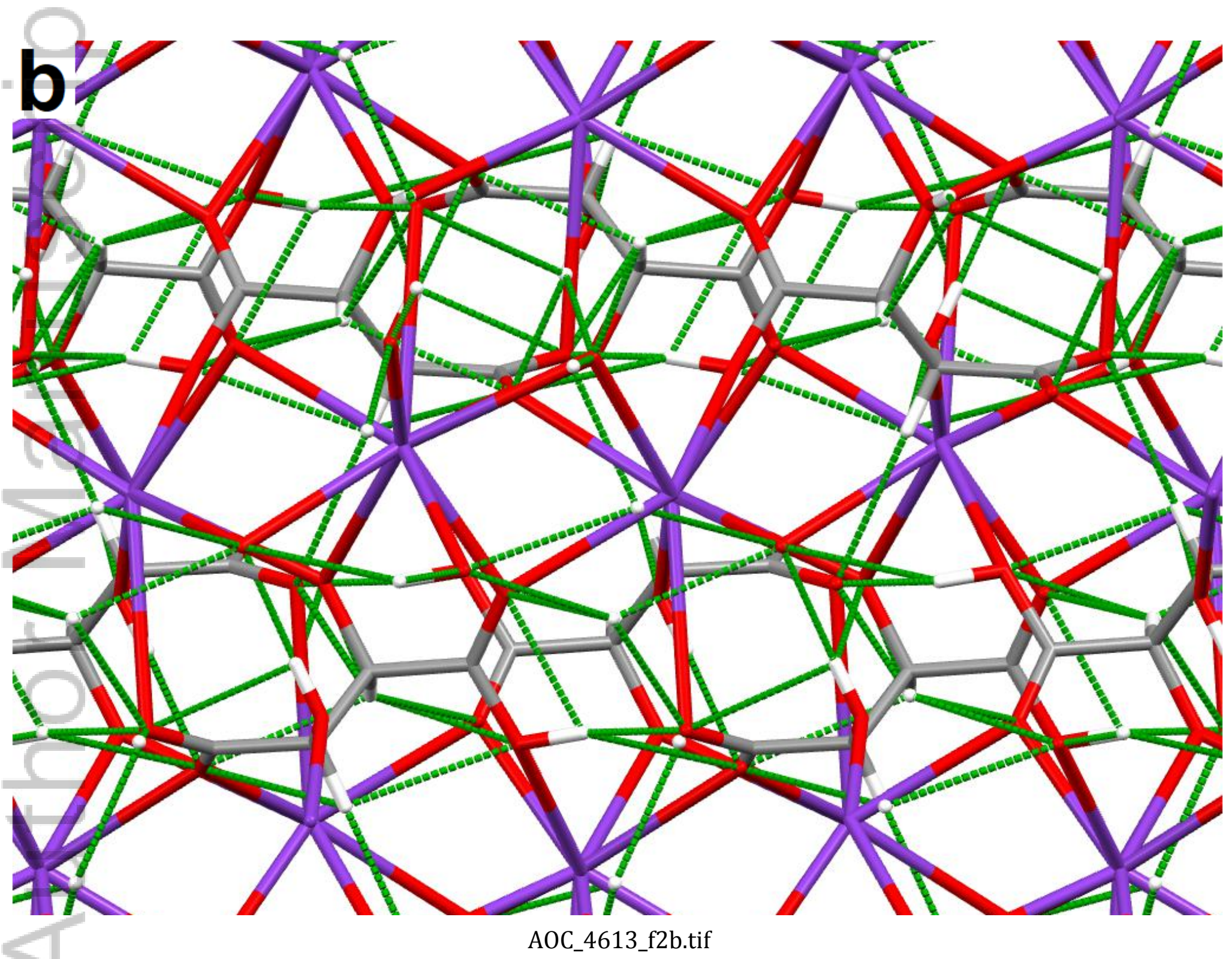

This article is protected by copyright. All rights reserved. 


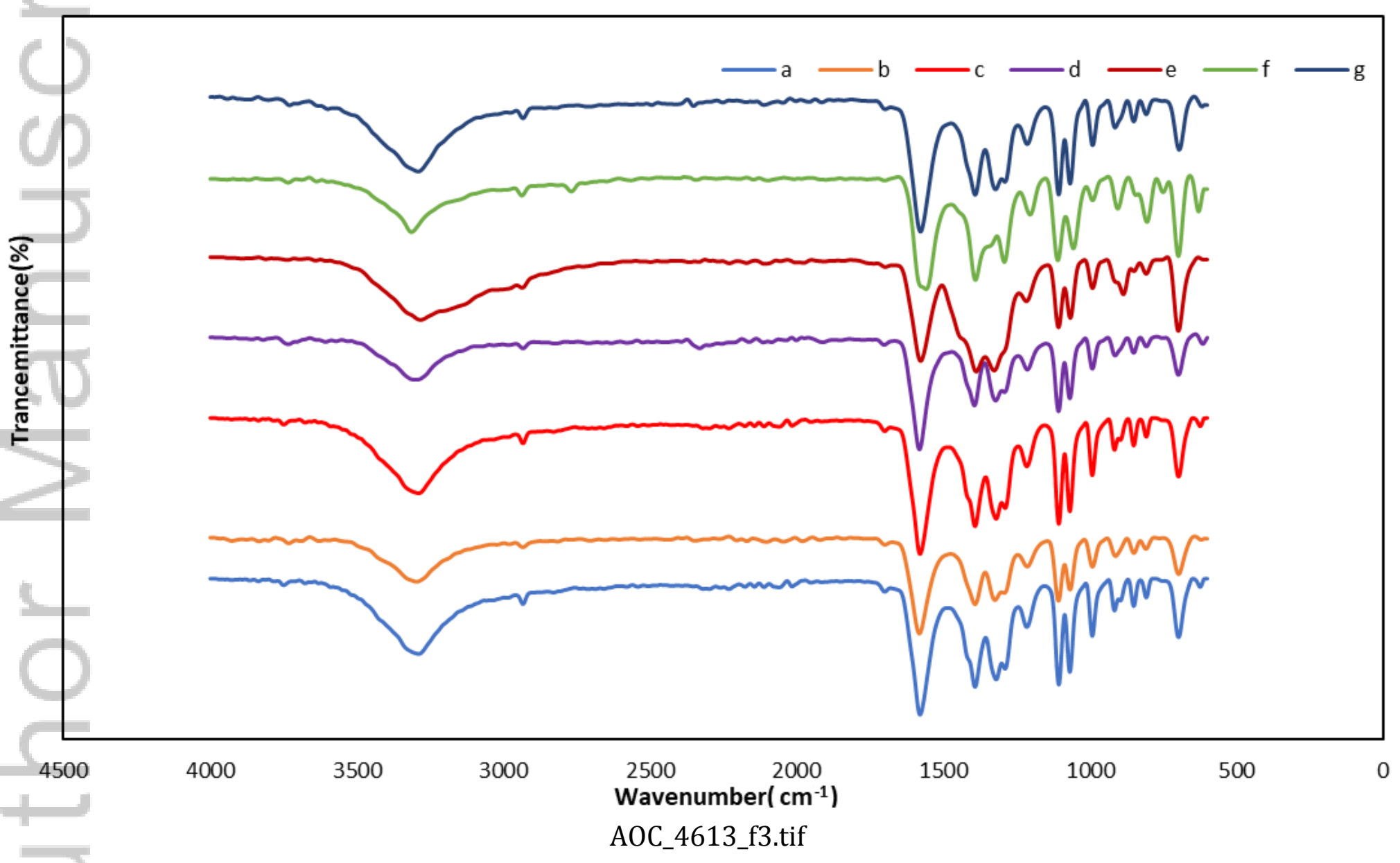

This article is protected by copyright. All rights reserved. 


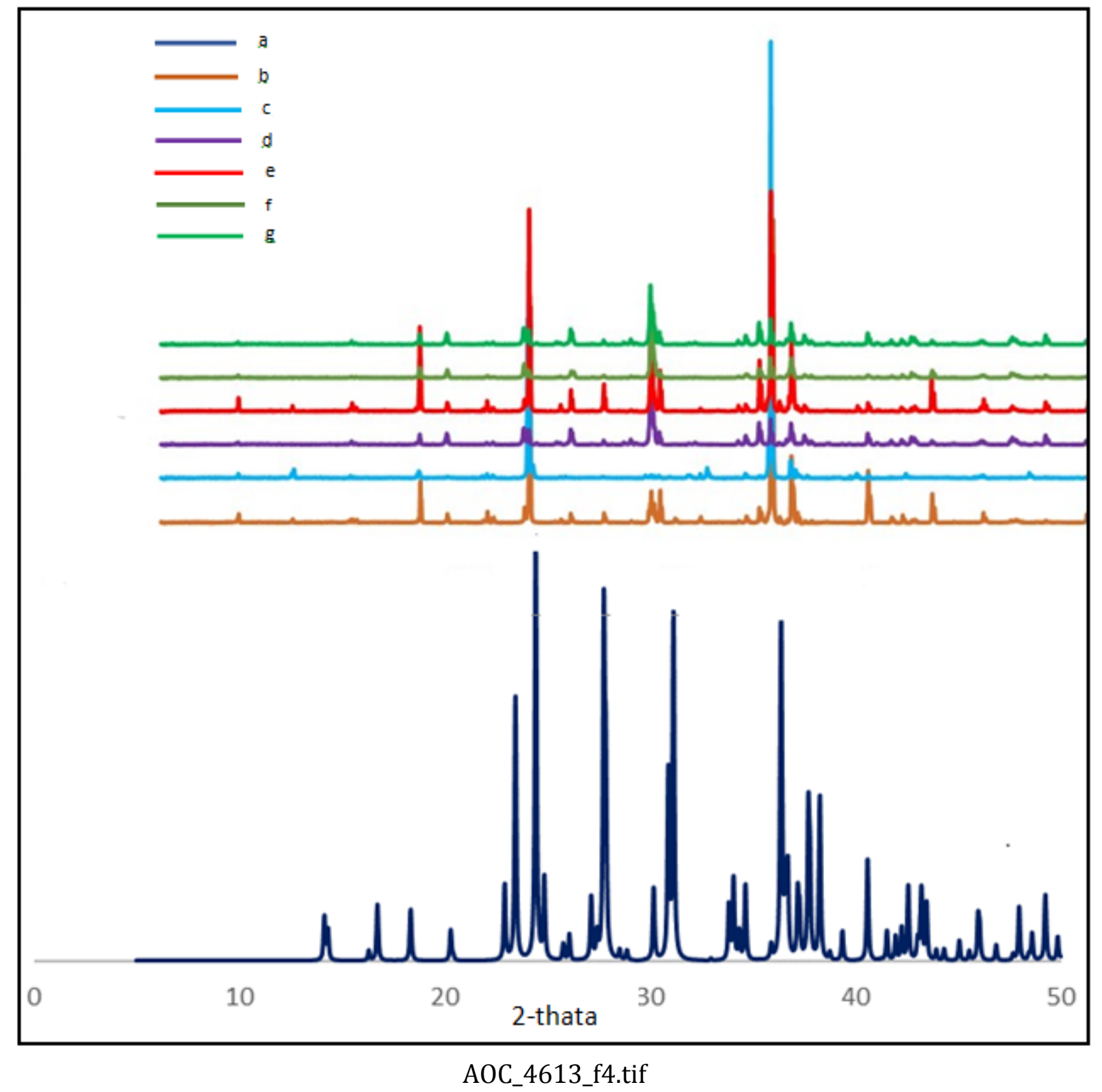

This article is protected by copyright. All rights reserved. 


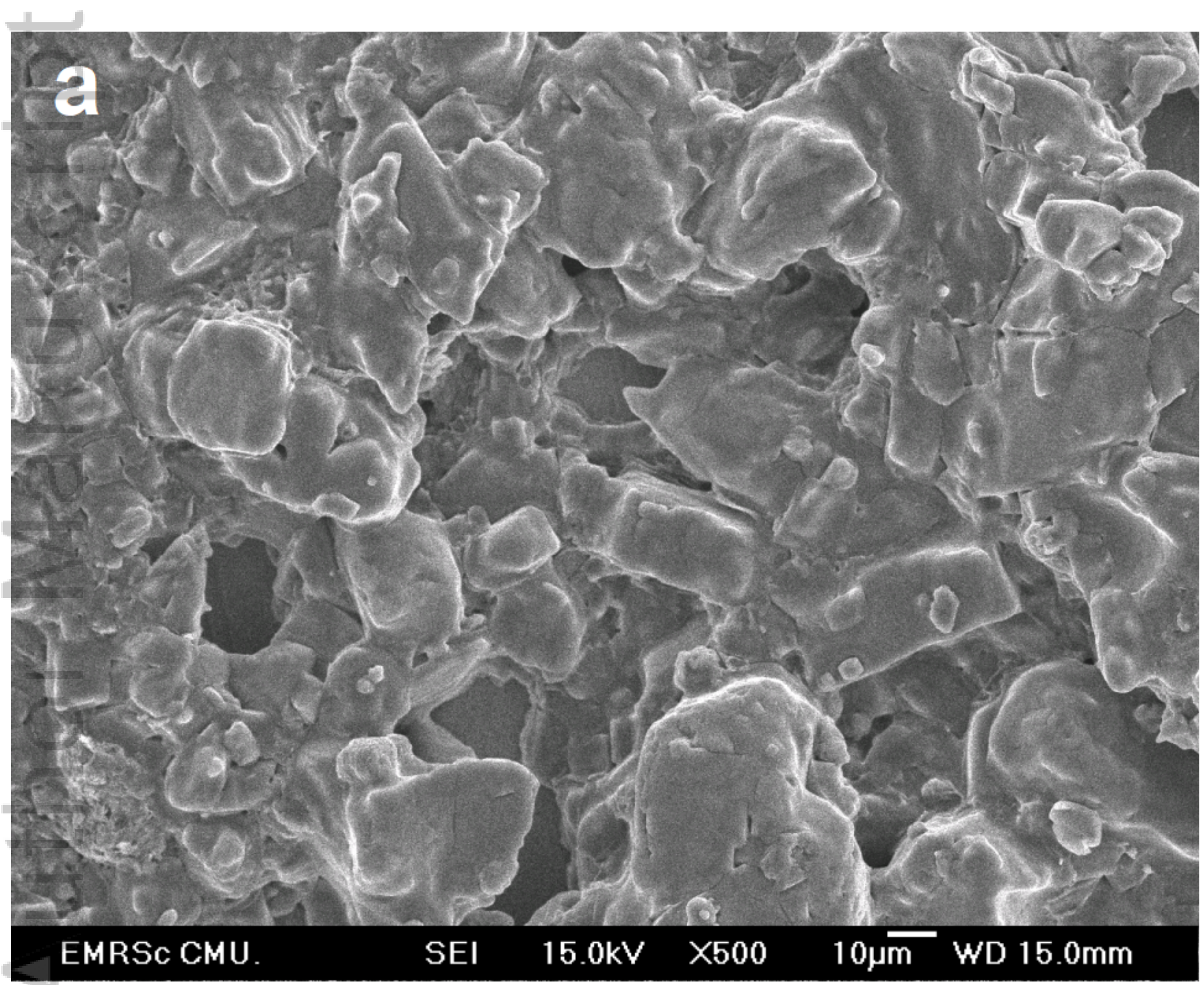

AOC_4613_f5a_first.tif

This article is protected by copyright. All rights reserved. 


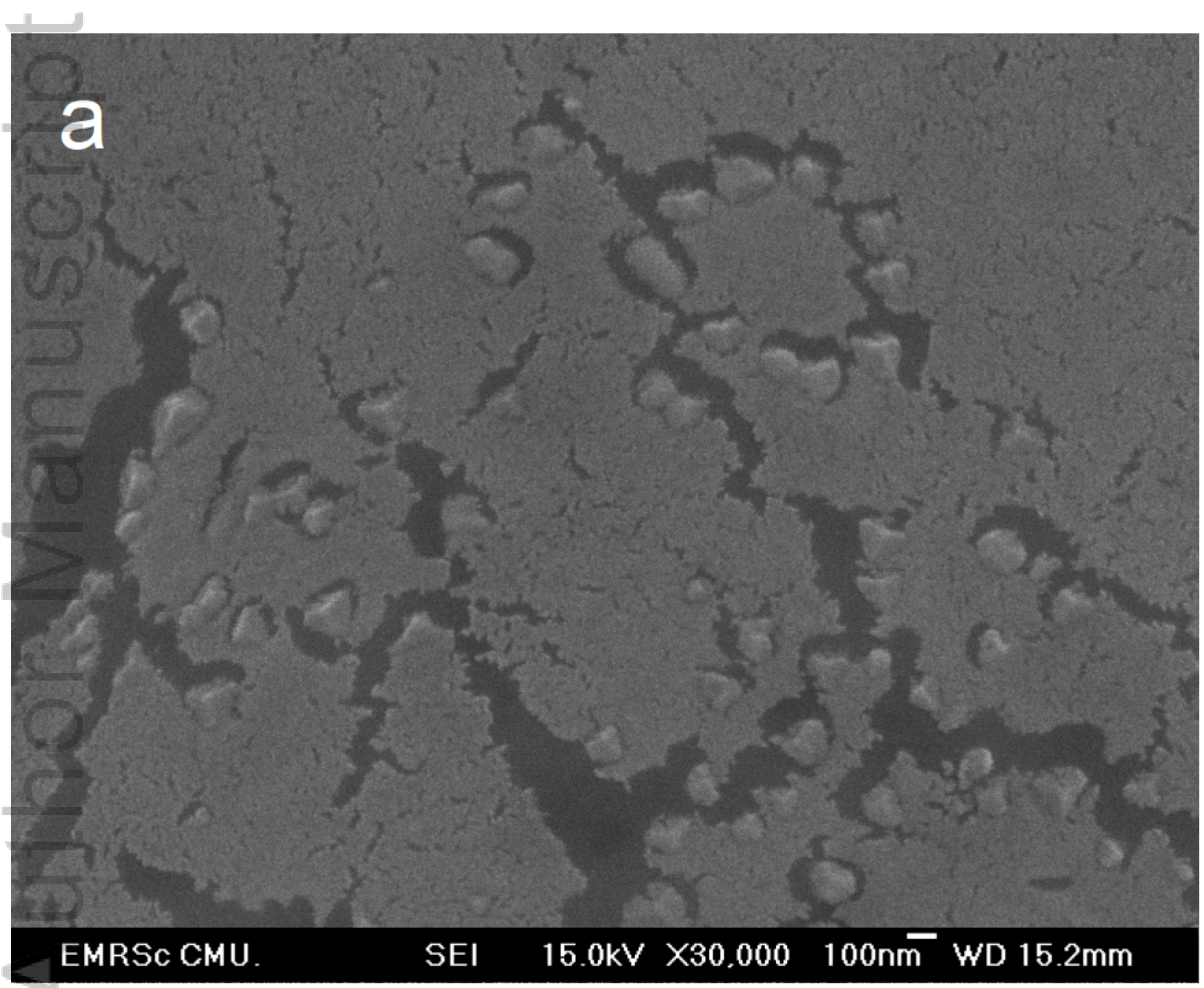

A0C_4613_f5a_second.tif

This article is protected by copyright. All rights reserved. 


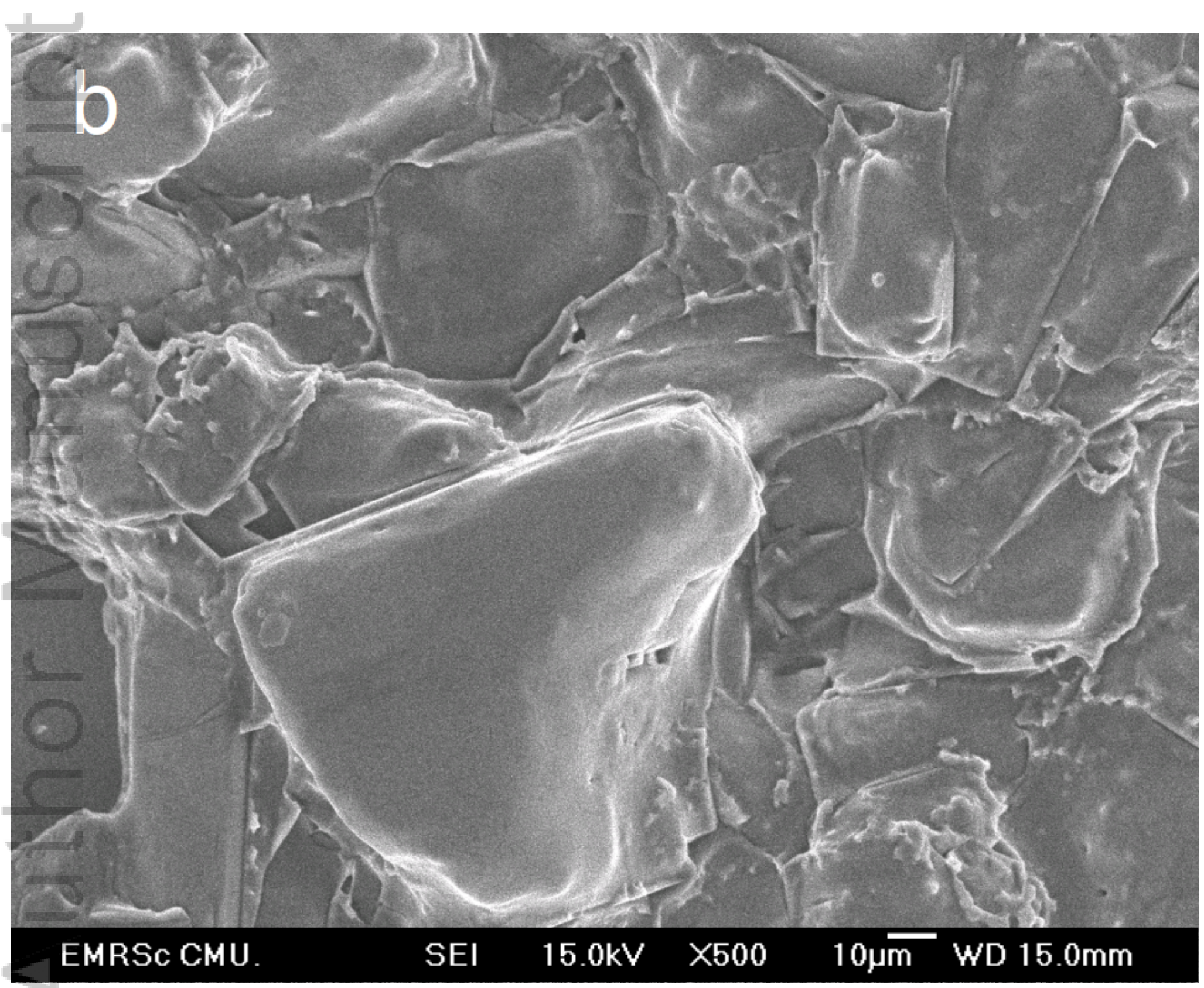

AOC_4613_f5b_first.tif

This article is protected by copyright. All rights reserved. 


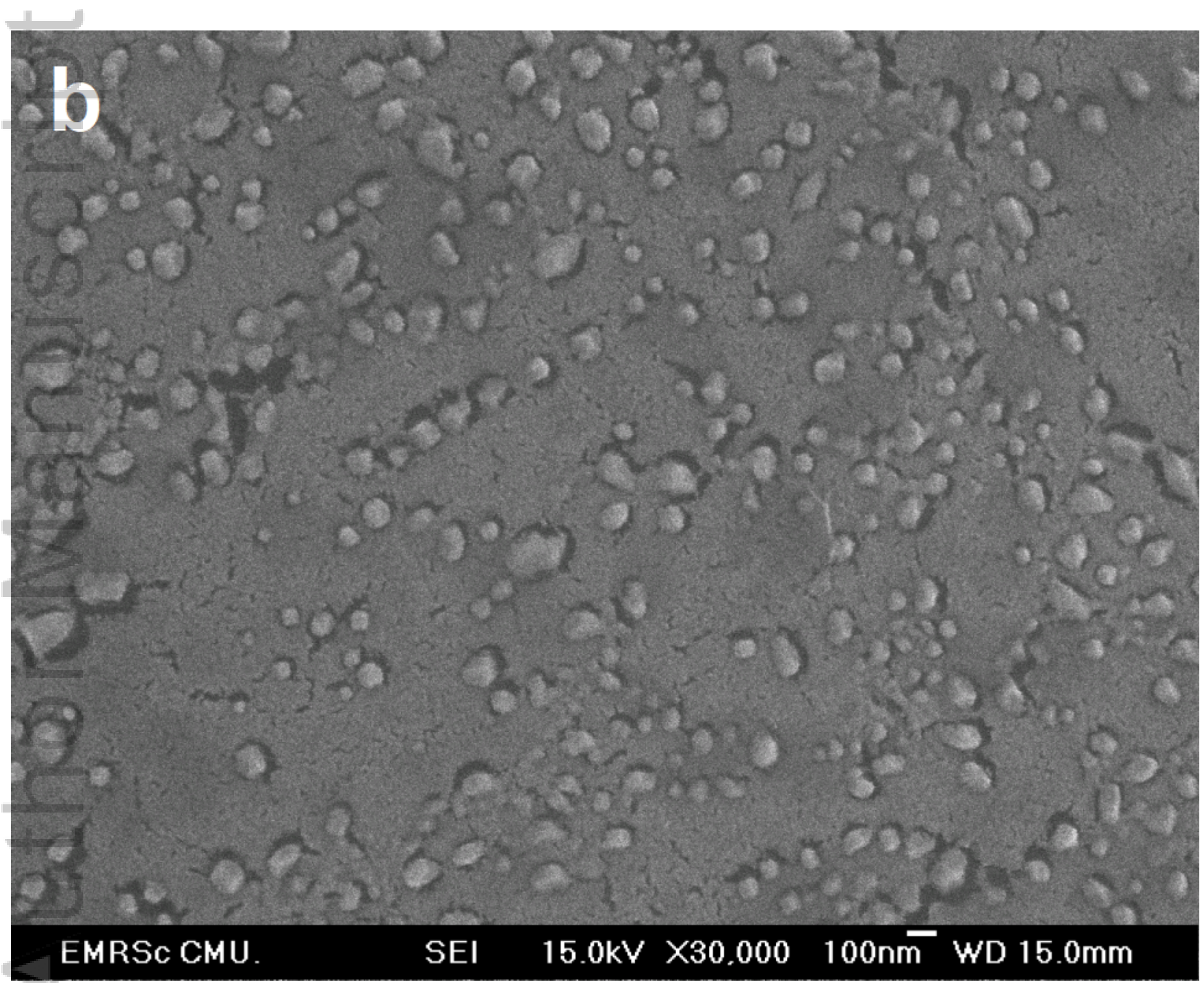

A0C_4613_f5b_second.tif

This article is protected by copyright. All rights reserved. 


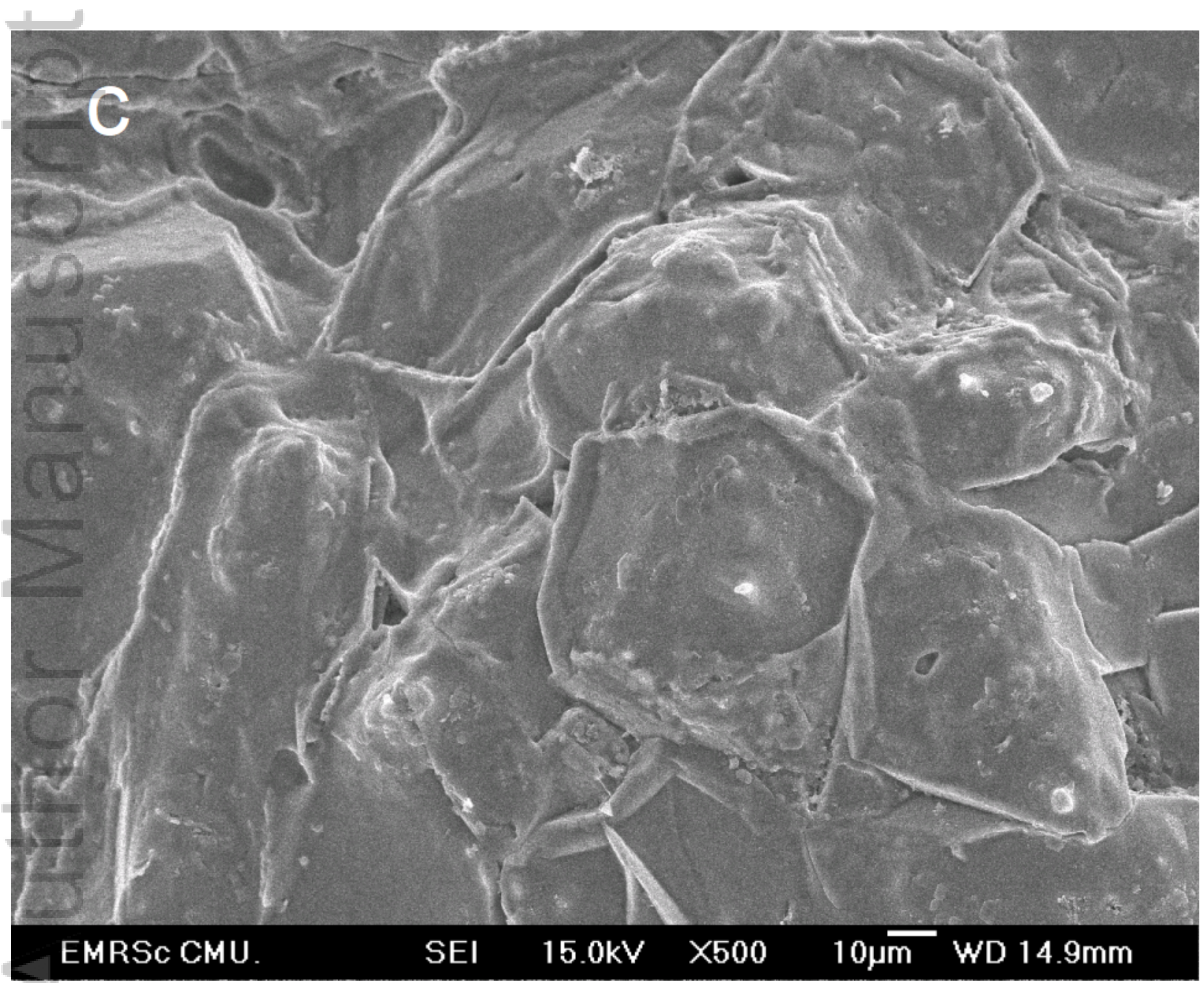

AOC_4613_f5c_first.tif

This article is protected by copyright. All rights reserved. 


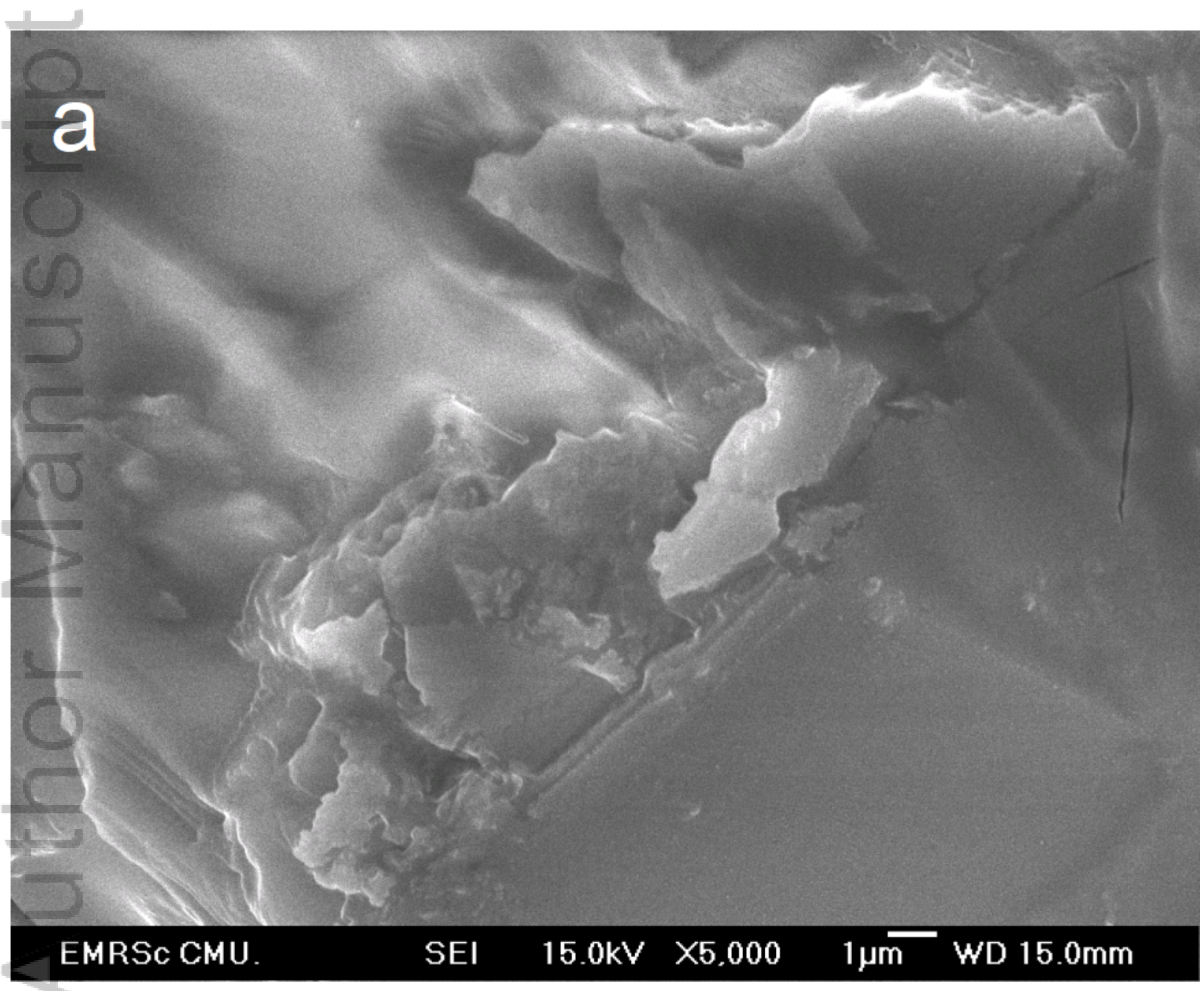

AOC_4613_f6a_first.tif

This article is protected by copyright. All rights reserved. 


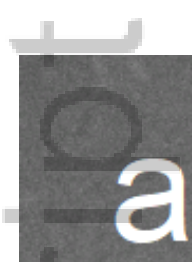

A0C_4613_f6a_second.tif 


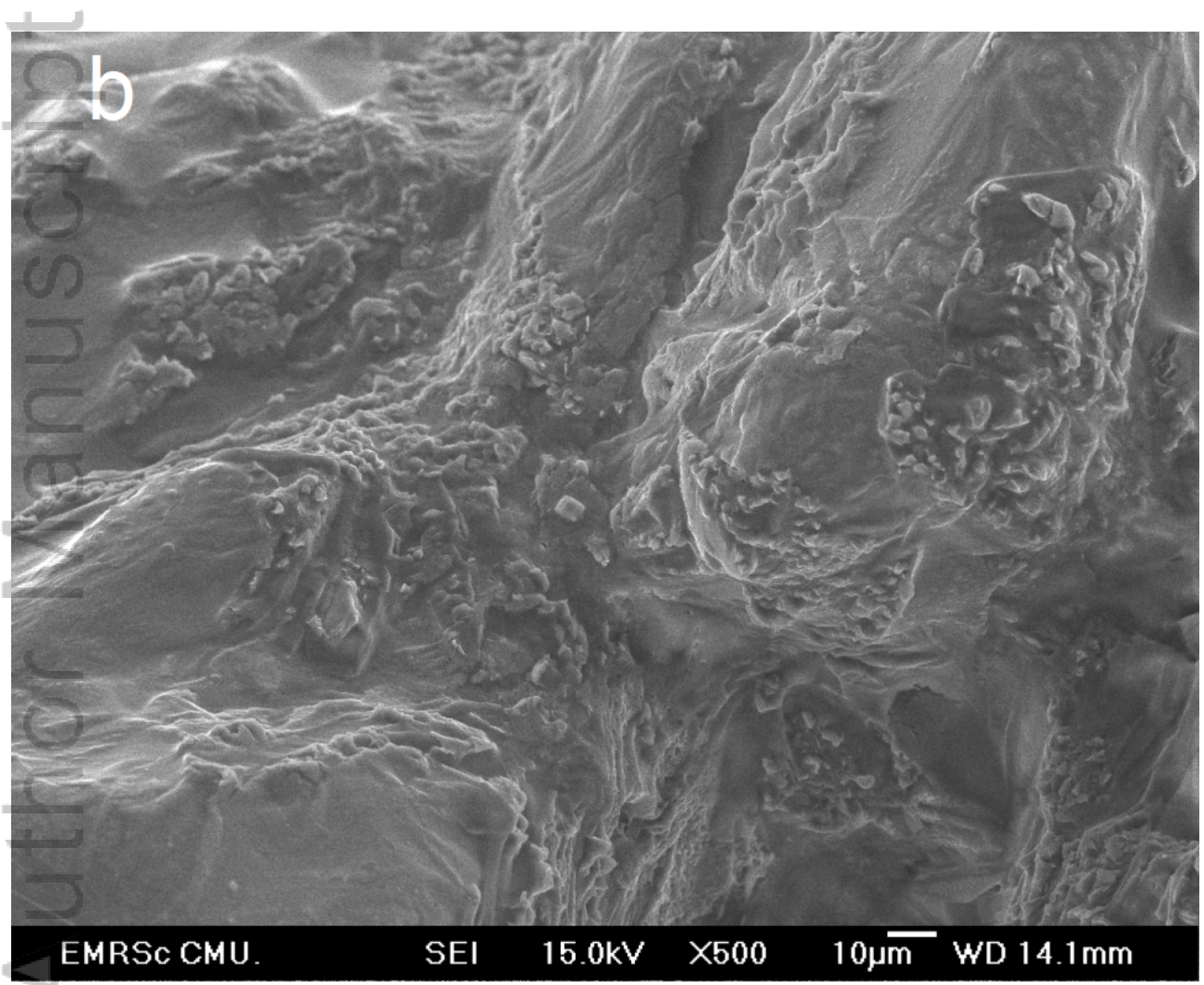

AOC_4613_f6b_first.tif

This article is protected by copyright. All rights reserved. 


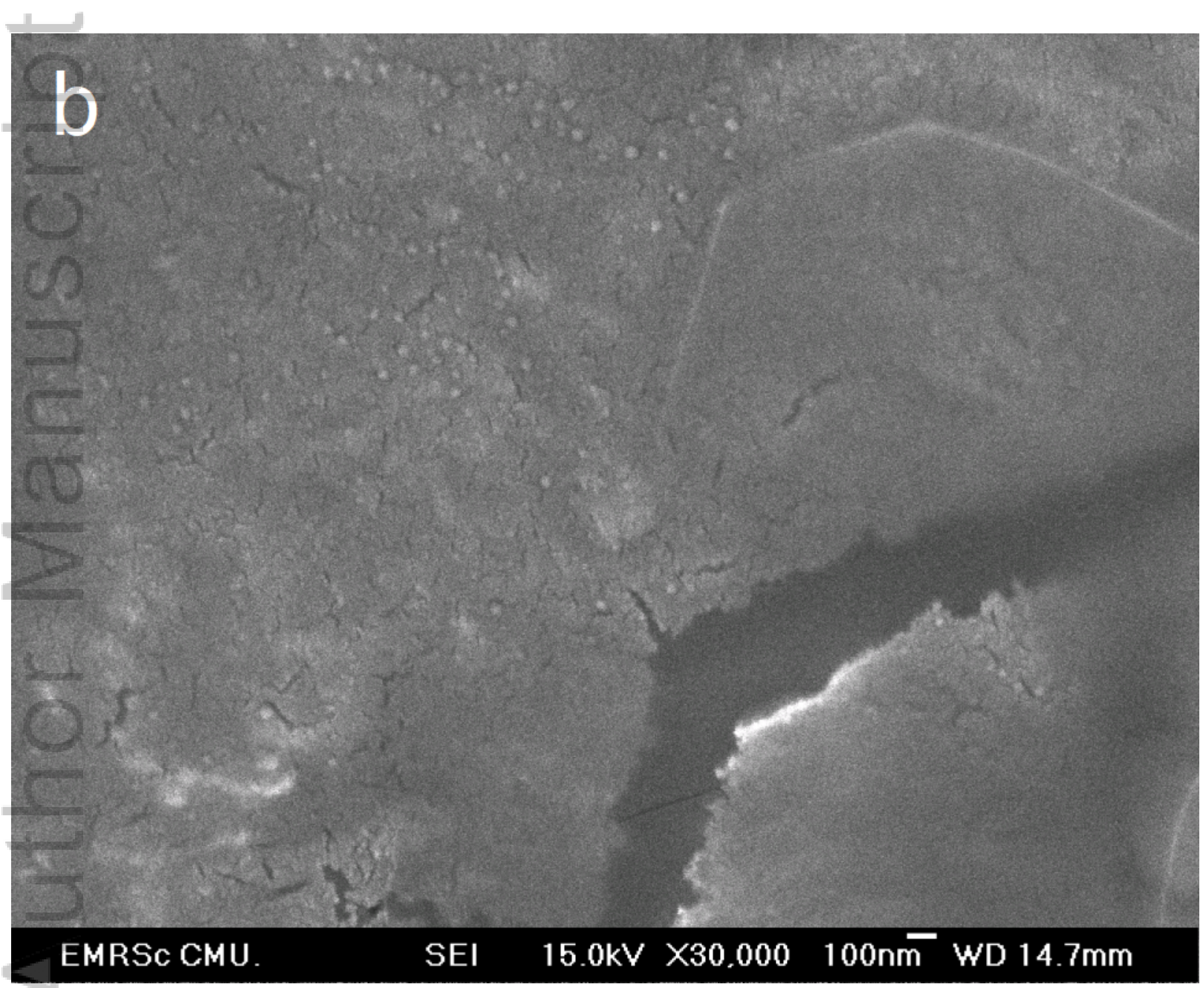

A0C_4613_f6b_second.tif

This article is protected by copyright. All rights reserved. 


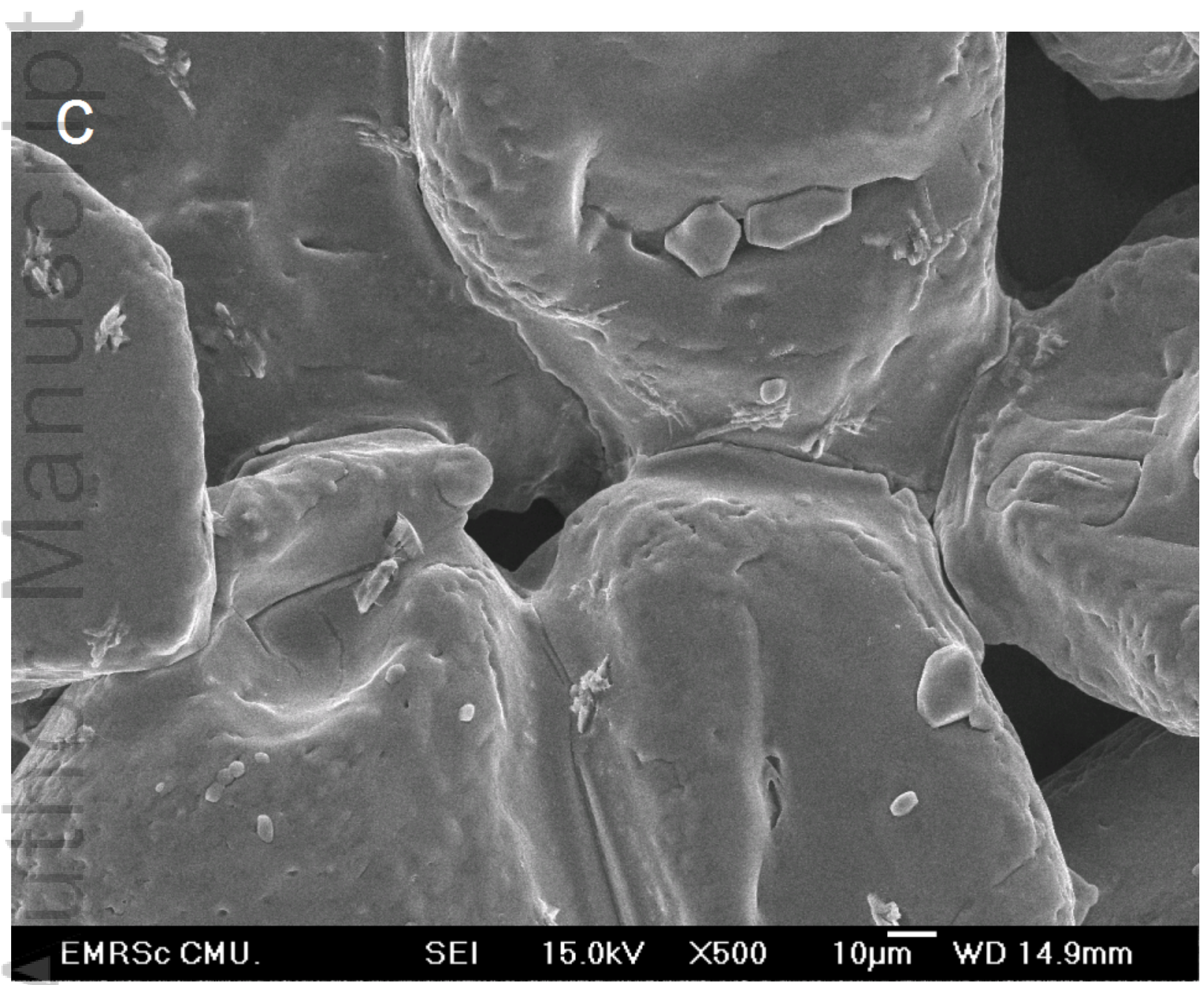

AOC_4613_f6c_first.tif

This article is protected by copyright. All rights reserved. 


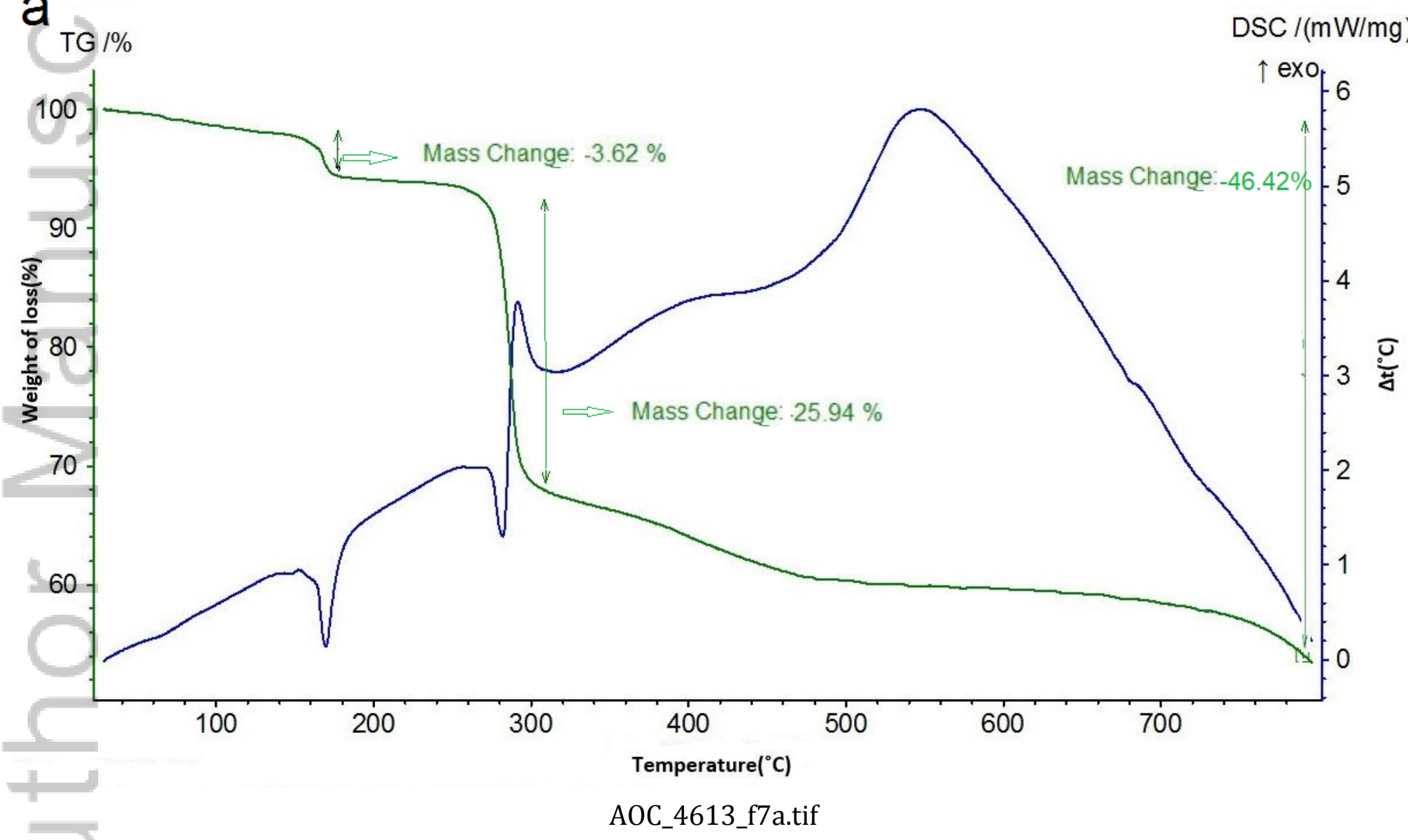

This article is protected by copyright. All rights reserved. 
b

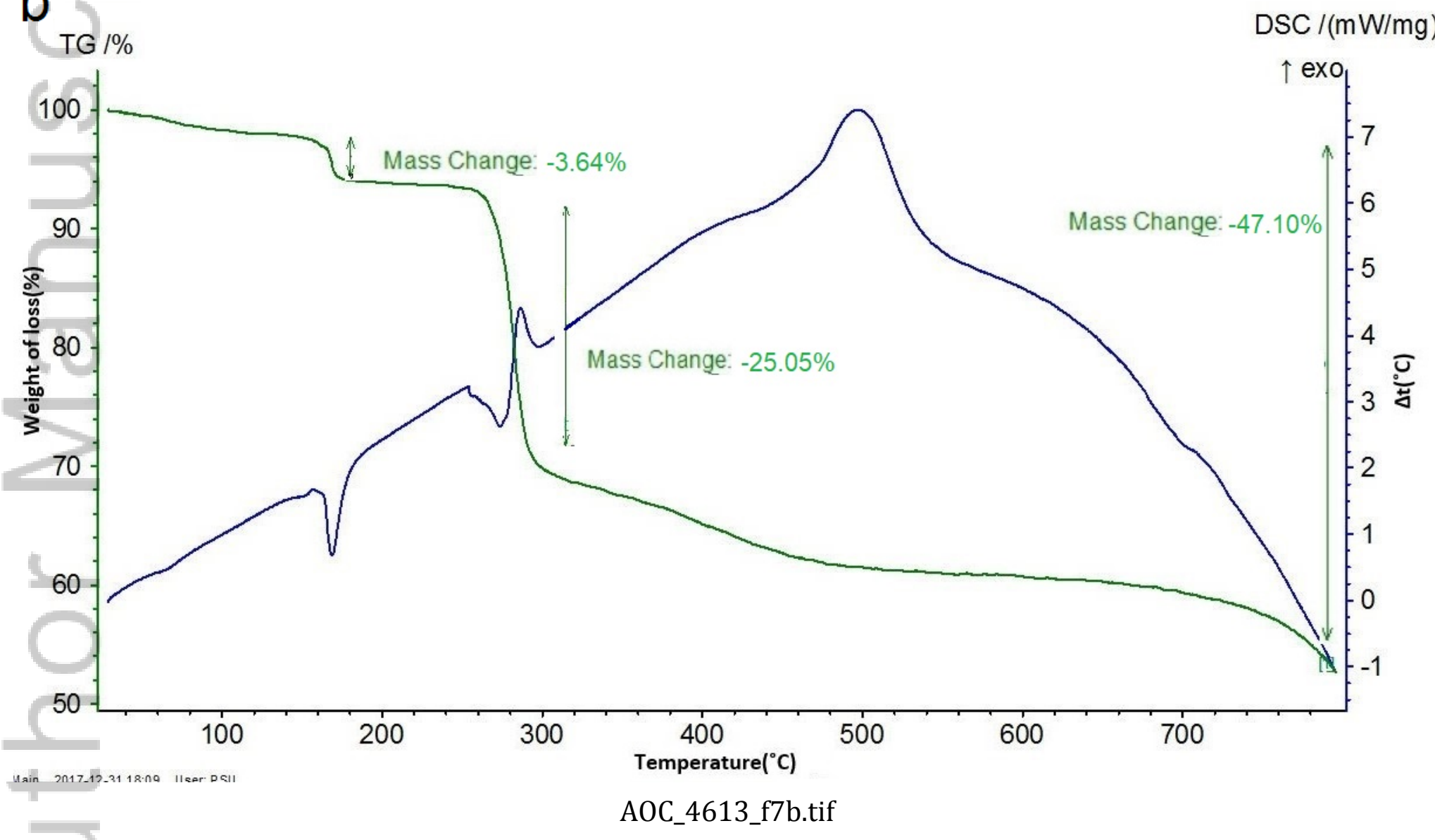

This article is protected by copyright. All rights reserved. 


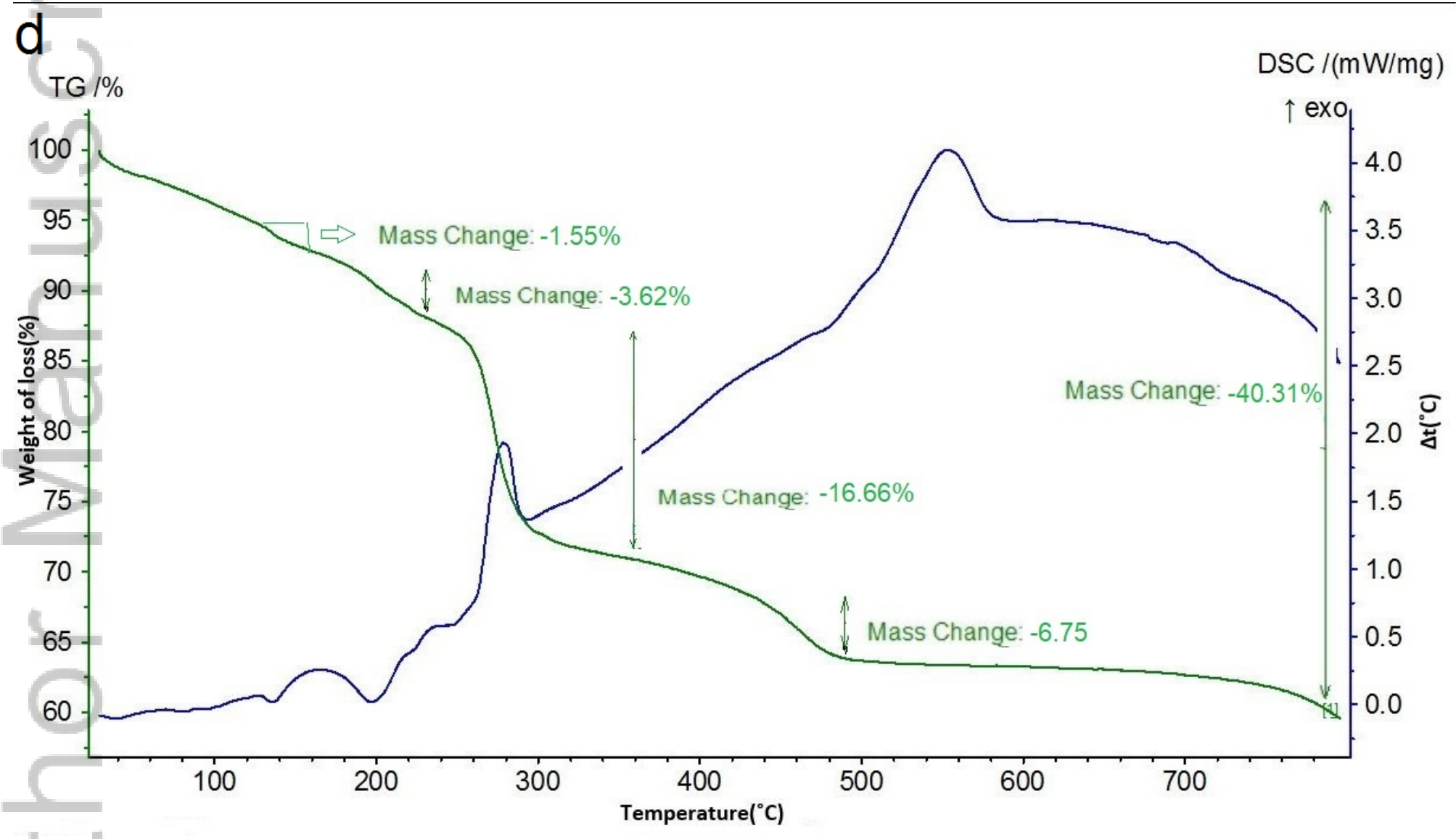

AOC_4613_f7d.tif

This article is protected by copyright. All rights reserved. 


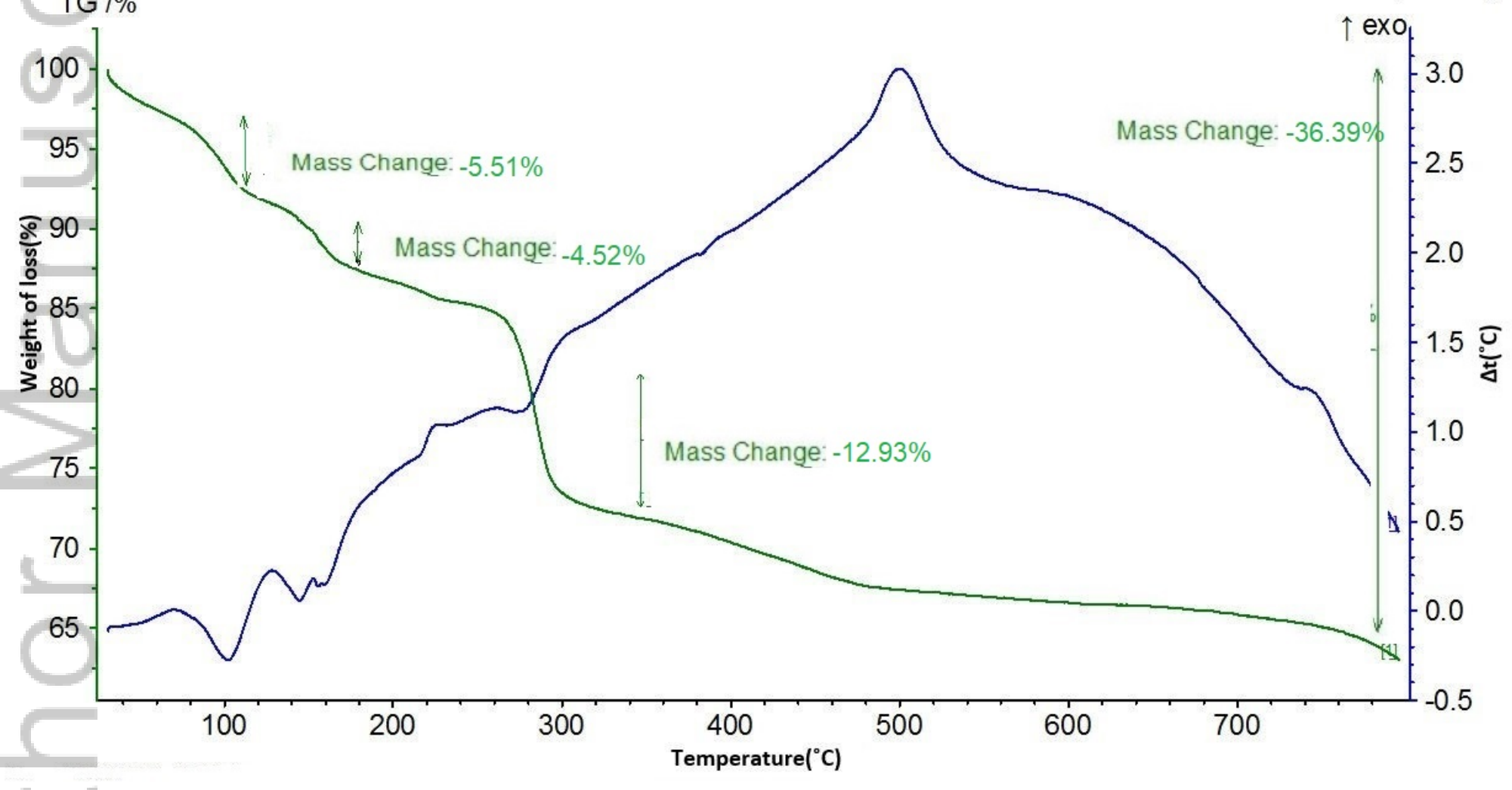

A0C_4613_f7e.tif 

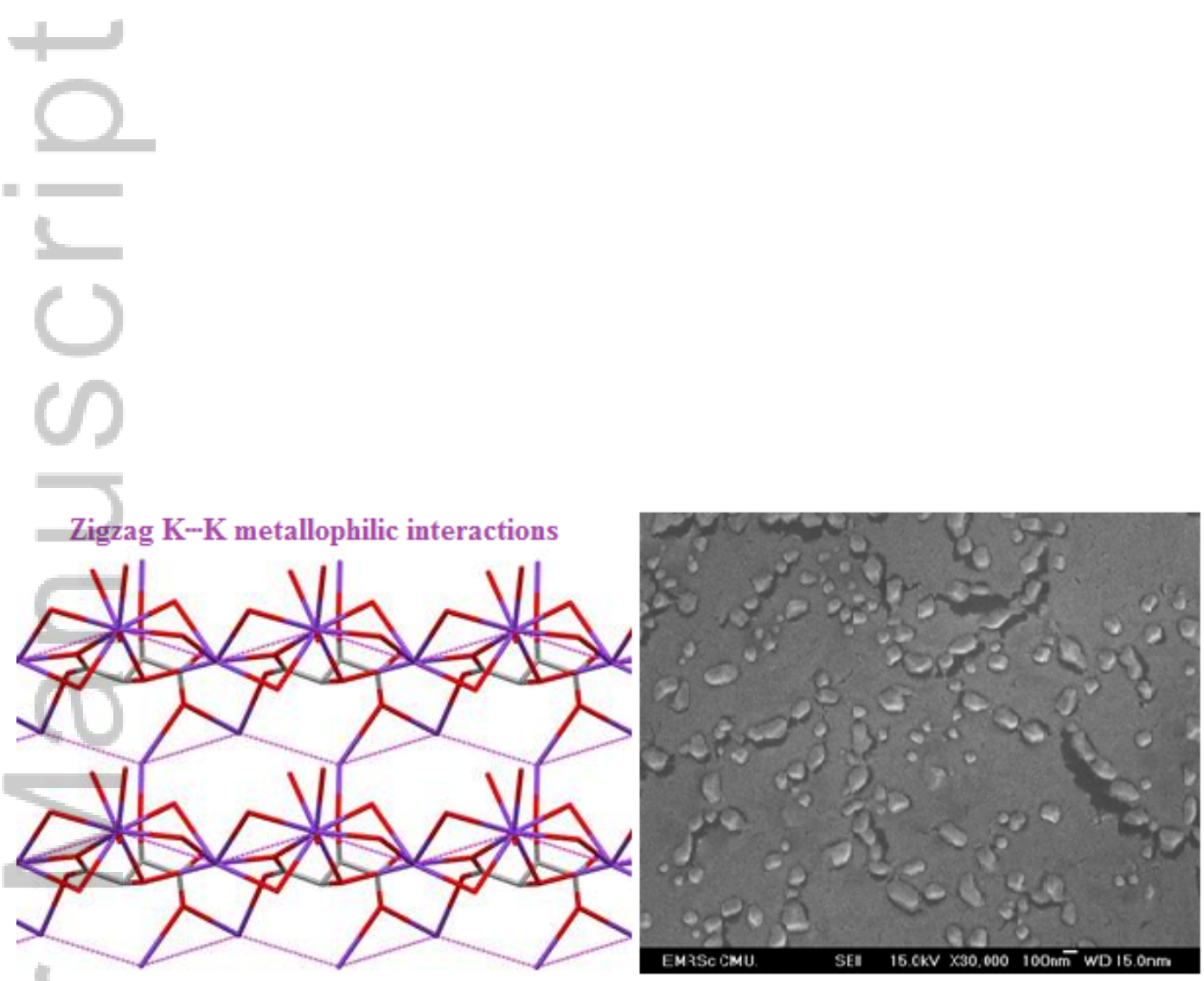

3D hydrogen bonding network

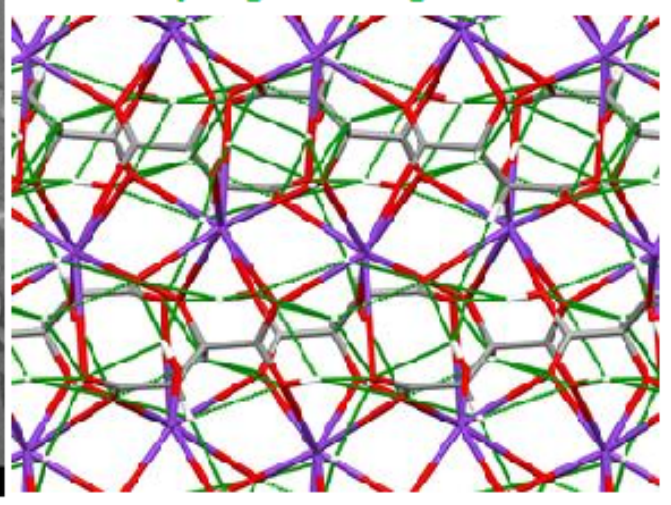
AOC_4613_GA.tif

This article is protected by copyright. All rights reserved. 